\title{
Deciphering the Iron Side of Stroke: Neurodegeneration at the Crossroads Between Iron Dyshomeostasis, Excitotoxicity, and Ferroptosis
}

\author{
Núria DeGregorio-Rocasolano', Octavi Martí-Sistac ${ }^{1,2 *}$ and Teresa Gasull1* \\ ${ }^{1}$ Cellular and Molecular Neurobiology Research Group, Department of Neurosciences, Germans Trias i Pujol Research \\ Institute (IGTP), Badalona, Spain, ${ }^{2}$ Department of Cellular Biology, Physiology and Immunology, Universitat Autònoma \\ de Barcelona, Bellaterra, Spain
}

OPEN ACCESS

Edited by:

Isabella Zanella,

Università degli Studi di Brescia, Italy

Reviewed by:

Alessandro Fanzani,

Università degli Studi di Brescia, Italy

Ashley lan Bush,

The Florey Institute of Neuroscience and Mental Health and The University

of Melbourne, Australia

Gladys Oluyemisi Latunde-Dada,

King's College London,

United Kingdom

*Correspondence:

Octavi Martí-Sistac

octavi.marti@uab.cat

Teresa Gasull

tgasull@igtp.cat;

teresagasull@yahoo.com

Specialty section: This article was submitted to

Neurodegeneration,

a section of the journal

Frontiers in Neuroscience

Received: 28 October 2018

Accepted: 25 January 2019

Published: 19 February 2019

Citation:

DeGregorio-Rocasolano N, Martí-Sistac O and Gasull T (2019)

Deciphering the Iron Side of Stroke:

Neurodegeneration at the Crossroads Between Iron Dyshomeostasis,

Excitotoxicity, and Ferroptosis.

Front. Neurosci. 13:85.

doi: 10.3389/fnins.2019.00085
In general, iron represents a double-edged sword in metabolism in most tissues, especially in the brain. Although the high metabolic demands of brain cells require iron as a redox-active metal for ATP-producing enzymes, the brain is highly vulnerable to the devastating consequences of excessive iron-induced oxidative stress and, as recently found, to ferroptosis as well. The blood-brain barrier (BBB) protects the brain from fluctuations in systemic iron. Under pathological conditions, especially in acute brain pathologies such as stroke, the BBB is disrupted, and iron pools from the blood gain sudden access to the brain parenchyma, which is crucial in mediating strokeinduced neurodegeneration. Each brain cell type reacts with changes in their expression of proteins involved in iron uptake, efflux, storage, and mobilization to preserve its internal iron homeostasis, with specific organelles such as mitochondria showing specialized responses. However, during ischemia, neurons are challenged with excess extracellular glutamate in the presence of high levels of extracellular iron; this causes glutamate receptor overactivation that boosts neuronal iron uptake and a subsequent overproduction of membrane peroxides. This glutamate-driven neuronal death can be attenuated by iron-chelating compounds or free radical scavenger molecules. Moreover, vascular wall rupture in hemorrhagic stroke results in the accumulation and lysis of iron-rich red blood cells at the brain parenchyma and the subsequent presence of hemoglobin and heme iron at the extracellular milieu, thereby contributing to ironinduced lipid peroxidation and cell death. This review summarizes recent progresses made in understanding the ferroptosis component underlying both ischemic and hemorrhagic stroke subtypes.

Keywords: iron, reactive oxygen species, ferroptosis, stroke, excitotoxicity, iron dyshomeostasis, neurodegeneration, transferrin saturation

Abbreviations: AIS, acute ischemic stroke; ALOX5: arachidonic acid lipoxygenase 5; APP, amyloid precursor protein; BBB, brain-blood barrier; CSF, cerebrospinal fluid; Dexras1, dexamethasone-induced Ras protein 1; DFO, deferoxamine; DMT1, divalent metal transporter 1; EAATs, excitatory amino acid transporters; FPN, ferroportin; FT, ferritin; FTH, ferritin heavy chain; GAPDH, glyceraldehyde-3-phosphate dehydrogenase; GPX4, glutathione peroxidase 4; GSH, glutathione; Hb, hemoglobin; HO, heme oxygenase; Hp, haptoglobin; Hpx, hemopexin; HTf, holotransferrin; ICH, intracerebral hemorrhage; I/R, ischemia/reperfusion; IREs, iron regulatory elements; IRPs, iron regulatory proteins; NAC, $N$-acetylcysteine; NMDA, $\mathrm{N}$-methyl-D-aspartate; NTBI, non-transferrin-bound iron; OGD, oxygen and glucose deprivation; PUFA, polyunsaturated fatty acids; ROS, reactive oxygen species; TIM, T-cell immunoglobulin and mucin domain-containing receptor; Tf, transferrin; TfR1, transferrin receptor 1; TfR2, transferrin receptor 2; TSAT, saturation of transferrin with iron; UTRs, untranslated regions; $\mathrm{X}_{\mathrm{c}}^{-}$, cystine/glutamate exchanger or antiporter, i.e., SLC7A11/xCT. 


\section{IRON TRANSPORT TO THE BRAIN: THE ROLE OF THE BLOOD-BRAIN BARRIER}

Iron is essential for life; numerous proteins require iron as a cofactor for their activity. Iron acts as an electron donor or acceptor, and thus is pivotal for oxygen transport (coordinated with hemoglobin), cellular respiration (as a part of hemecontaining cytochromes and proteins containing $\mathrm{Fe}-\mathrm{S}$ groups in the electron transport chain), and DNA synthesis (in ribonuclease reductase). Moreover, in the nervous system, iron is essential for myelinization and neurotransmitter biosynthesis.

Iron exists both as $\mathrm{Fe}^{2+}$ and $\mathrm{Fe}^{3+}$; redox-active and cycling between these two states lead to the generation of reactive oxygen species (ROS) through the Fenton reaction. The ROS promote oxidative stress and cause extensive lipid peroxidation (Gutteridge et al., 1979). The brain is particularly vulnerable to lipid peroxidation damage because it is rich in polyunsaturated fatty acids (PUFAs) and iron, but relatively poor in antioxidant defenses (Cobley et al., 2018). The iron content remarkably differs across different brain regions: it is high in the striatum, medium in the hippocampus and cortex, and low in the pons and medulla (Ramos et al., 2014). Although it has recently attracted considerable attention, iron metabolism in the brain is yet not completely understood as that in other murine tissues (Ashraf et al., 2018). Brain imports iron from systemic circulation, and the levels of iron are determined by diet, intestinal iron absorption, release of iron initially stored in the hepatocytes, and export of iron recycled from macrophages. In addition, the levels of iron in the plasma are regulated by the hormone hepcidin through its effect on the transmembrane iron export protein ferroportin (FPN), which is mainly present at the cell membrane of macrophages, hepatocytes, and enterocytes.

In the blood and most other extracellular fluids, iron is essentially carried bound with high affinity to the iron transport protein transferrin (Tf), which shields $\mathrm{Fe}^{3+}$ from redox activity. In addition to Tf, iron also associates with other carrier proteins in the blood such as ferritin (FT), haptoglobin (Hp), Hpx, or albumin. Recently, half a dozen different non-proteinaceous lowmolecular-weight iron species $(<10 \mathrm{KDa})$ have been shown to exist in the blood (Dziuba and Lindahl, 2018); further studies are required to determine the precise identity and physiological role of these species. Once iron is bound to $\mathrm{Tf} \mathrm{Fe}^{3+}$ is rendered redox-inactive and virtually non-exchangeable or displaceable by other physiological metals or molecules. Tf-iron complexes circulate in the blood until they bind transferrin receptors (TfRs) in cellular membranes of target cells. In general, in non-ironoverload conditions, little, if any, non-transferrin-bound iron (NTBI) is found in the blood of healthy individuals (Gaasch et al., 2007). The high affinity of Tf for iron and the large amount of Tf in the blood exceed the total requirement for iron binding; in normal human blood, the saturation of transferrin with iron (TSAT) is only of around 30\% (De Valk et al., 2000; Van Dijk et al., 2008). Therefore, iron transport to the brain is mainly from iron-loaded transferrin (holotransferrin, HTf) through the endothelial cells of the BBB and the epithelium of the choroid plexuses and arachnoid membrane, the blood-cerebrospinal fluid (CSF) barrier.
Although barrier cells of the brain form tight junctions laterally, epithelial cells of the choroid plexuses are fenestrated and more permeable than the endothelial cells of the BBB (Strazielle and Ghersi-Egea, 2016). The abluminal side of brain capillary endothelial cells is surrounded by pericytes and astrocytes of the neurovascular unit that provide extra structural and functional support. TfRs are abundantly expressed in the luminal side of membranes of polarized endothelial cells; once they bind Tf, the TfR-Tf complexes undergo endocytosis. The following steps are still controversial, and different pathways are thought to be involved in brain iron acquisition (Bradbury, 1997; Khan et al., 2018). Thus far, the main contribution to this process is thought to include the following pathways: (1) endocytic vesicles containing TfR-HTf traveling from the luminal membrane to fuse to the abluminal membrane and exocytose either HTf or free iron into the brain extracellular space; (2) under low $\mathrm{pH}$ conditions within the endosome of endothelial cells, as in most cell types, iron is extracted from Tf, converted to $\mathrm{Fe}^{2+}$ by endosomal ferrireductases such as the six-transmembrane epithelial antigen of prostate protein 3 (Steap3), and released to the cytosol through divalent metal transporter 1 (DMT1) or the ion channels TRPML, also known as mucolipin 1 or MCOLN1 (detailed information can be found in references Luck and Mason, 2012; Skjorringe et al., 2015). Subsequently, $\mathrm{Fe}^{2+}$ from the cytosol is exported through FPN present in the abluminal membrane of endothelial cells, which are in contact with astrocytes expressing ceruloplasmin, that rapidly oxidize $\mathrm{Fe}^{2+}$ to $\mathrm{Fe}^{3+}$ (this Tf/TfR endocytosis mechanism is common for endothelial and neuronal cells and is depicted in Figures 1, 2). A recent study performed using comprehensive mathematical models concluded that optimal iron homeostasis is dependent on the degree of saturation and the transport of HTf across the BBB from the blood (Khan et al., 2018).

In addition, in mice exposed to experimental stroke under normal iron conditions, iron deposits in the microvasculature were observed early in the border zone of the damaged areas (Desestret et al., 2009), suggesting that, when signaled, the BBB might function as an iron reservoir from which iron is released into the brain. Regarding signaling to release, in bovine retinal endothelial cells, the FPN-mediated iron export is known to be blocked by the FPN inhibitor hepcidin (Hadziahmetovic et al., 2011). In addition, new insights into the communication between systemic iron status and brain iron uptake reveal the regulation of brain iron uptake at the level of brain microvascular endothelial cells rather than the $\mathrm{BBB}$ acting merely as a retaining wall (Chiou et al., 2018b). In support of this regulatory hypothesis, endothelial microvascular cell distribution of TfR is altered in luminal, intracellular, and abluminal membranes depending on brain iron status (Simpson et al., 2015), and microvascular cell iron availability and efflux have been found to be tightly modulated by diffusible ceruloplasmin and hepcidin released from astrocytes surrounding the $\mathrm{BBB}$ (McCarthy and Kosman, 2014). Moreover, a recent study showed that inhibition of DMT1 alters the transport of iron and Tf across the endothelial cells and proposed that the levels of irondevoid Tf (apotransferrin) and iron delivered to the brain are strongly regulated by the ratio apotransferrin:HTf as well as by 

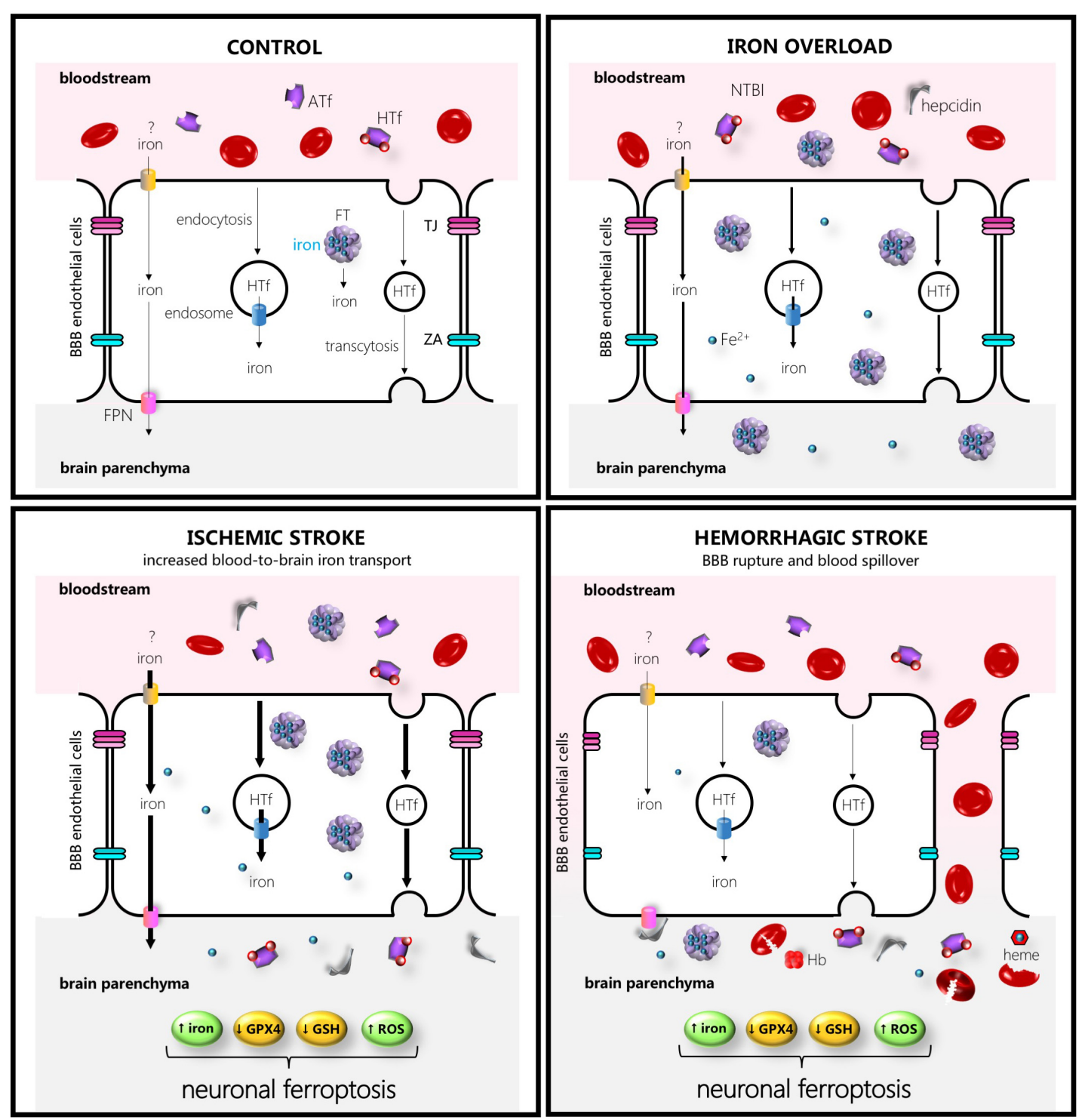

FIGURE 1 | Schematic drawing of some of the main players in iron transport to the brain in control (left hand upper side), iron overload (right-hand upper side), ischemic stroke (left-hand lower side), or intracerebral hemorrhage (right-hand lower side). The thicker the arrows the more increased the transport. Abbreviations: ATf, apotransferrin; FPN, ferroportin; HTf, holotransferrin; FT, ferritin, GPX4, glutathione peroxidase 4; GSH, glutathione; Hb, hemoglobin; NTBI, non-transferrin-bound iron; ROS, reactive oxygen species; TJ, tight junction; ZA, zonula occludens.

hepcidin levels in the extracellular fluid of each brain region (Duck et al., 2017).

Further, very recently, a new function for FT heavy chain (FTH) as a transporter of NTBI across the BBB by binding to the T-cell immunoglobulin and mucin domain-containing 1 receptor 1 (TIM-1) has been reported in human endothelial cells (Chiou et al., 2018b).

In the context of physiological iron-overload conditions found, for instance, in individuals on iron-rich diets, a significant pool of NTBI is found in the blood and might be readily absorbed by microvascular endothelial cells. This effect might be relevant considering that regional differences in the brain uptake of ${ }^{59} \mathrm{Fe}-\mathrm{NTBI}$ versus ${ }^{59} \mathrm{Fe}-\mathrm{TfR}$ have been reported (Deane et al.,
2004), and that ${ }^{59} \mathrm{Fe}-\mathrm{NTBI}$ seems to be transported faster than ${ }^{59} \mathrm{Fe}$-TfR into the brain parenchyma of iron-overloaded diseasefree mice. Furthermore, the iron storage protein FT has been found to be upregulated in epithelial cells of the choroid plexus and endothelial cells of the brain during systemic iron overload (Tripathi et al., 2017).

\section{IRON UPTAKE AND HANDLING BY PARENCHYMAL BRAIN CELLS}

Once in the brain interstitial fluid, both TBI and NTBI are potential iron sources for brain cells (Gaasch et al., 2007); unlike 


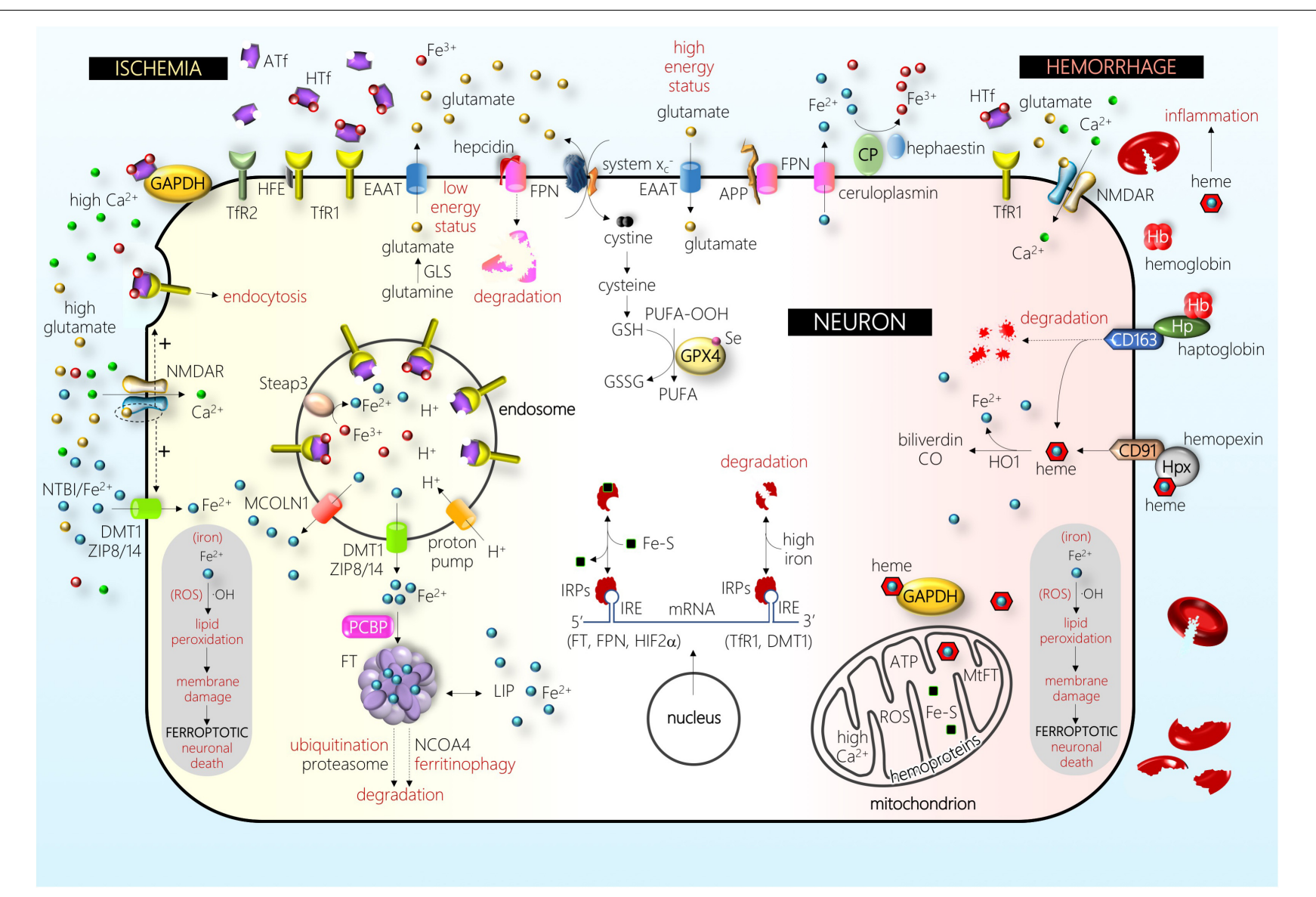

FIGURE 2 | Schematic drawing of some of the main players in a neuron under ischemic (left-hand side) and hemorrhagic (right-hand side) stress (see text for details). Abbreviations: APP, amyloid precursor protein; ATf, apotransferrin; CD163, hemoglobin/haptoglobin receptor; CD91, heme/hemopexin receptor; CO, carbon monoxide; CP, ceruloplasmin; DMT1, divalent metal transporter 1; EAAT, excitatory amino acid transporter; $\mathrm{Fe}^{2+}$, ferrous iron; $\mathrm{Fe}^{3+}$, ferric iron; $\mathrm{Fe}_{-} \mathrm{S}$, iron-sulfur cluster; FPN, ferroportin; FT, ferritin; GAPDH, glyceraldehyde-3-phosphate dehydrogenase; GLS, glutaminase; GPX4, glutathione peroxidase 4; GSH, glutathione; GSSG, glutathione disulfide; Hb, hemoglobin; HFE, hereditary hemochromatosis protein; HIF, hypoxia-inducible factor; HO1, heme oxygenase 1; Hp, haptoglobin; Hpx, hemopexin; HTf, holotransferrin; IRE, iron-responsive element; IRPs, iron regulatory proteins; LIP, labile iron pool; MCOLN1, mucolipin 1; MtFT, mitochondrial ferritin; NCOA, nuclear receptor coactivator; NMDAR, NMDA receptor; NTBI, non-transferrin-bound iron; OH, hydroxyl radical; PCBP, poly(rC)-binding protein; PUFA, poly-unsaturated fatty acid; PUFA-OOH, PUFA peroxide; ROS, reactive oxygen species; Se, selenium; Steap, six-transmembrane epithelial antigen of prostate; system $X_{c}^{-}$, cystine-glutamate antiporter; TfR1, transferrin receptor 1; TfR2, transferrin receptor 2; ZIP8/14, zinc transporters 8/14. The picture depicts the effect of one of the major players in the pathophysiology of brain I, the disruption of glutamatergic neurotransmission homeostasis that produces elevated extracellular glutamate levels, overactivation of the NMDA subtype of glutamate receptors (NMDAR), and excitotoxic cell death. In the recent past, different authors have shown that this NMDAR overactivation boosts neuronal iron uptake and produces an iron-dependent form of neuronal death associated with massive lipid peroxidation that fits with the definition of ferroptosis. Further, in the hemorrhage type of stroke, iron derived from hemoglobin and/or heme enters neurons and produces massive lipid peroxidation. Damage by ischemic and hemorrhagic stroke is alleviated by the inhibitors of ferroptosis.

blood Tf, CSF Tf is considered to be completely saturated with iron (Bradbury, 1997). Within the extracellular milieu of the brain parenchyma, iron is carried loaded into Tf or bound to low-molecular-weight molecules such as citrate, ascorbate, or ATP. Each brain cell type uptakes extracellular TBI or NTBI depending on the iron-transport receptors and channels present in their membranes and, physiologically, safely handles iron by using the network of proteins they specifically express to import, store, traffic, and export iron. Players of cellular iron homeostasis are cell type-specific, and the list of proteins involved in iron homeostasis is still growing. As an example of iron-related new proteins, only 3 years ago, the members of the ZIP family of metal ion transporters Zip8 and Zip14, which, unlike the DMT1 transporter are only active at normal physiological $\mathrm{pH}$, were reported to be expressed by hippocampal neurons, and Zip8 was found to play a major role in the accumulation of NTBI by hippocampal neurons (Ji and Kosman, 2015), whereas both Zip8 and Zip14 were considered to play a role in iron homeostasis in rat retina (Sterling et al., 2017).

\section{Receptors Involved in Iron Uptake by Brain Cells}

In addition to the well-known TfR1 as a main player of the $\mathrm{TfR} / \mathrm{Tf}$ endocytic pathway in most brain cells, other proteins, e.g., transferrin receptor 2 (TfR2) (Kawabata, 2018) or glyceraldehyde- 
3-phosphate dehydrogenase (GAPDH) (Raje et al., 2007), have been described as receptors for Tf and are currently being investigated. TfR1 binds HTf with a Kd of $1 \mathrm{nM}$; it is expressed in response to changes in iron levels through modulation by iron regulatory elements (IREs) present in its mRNA and binds hereditary hemochromatosis HFE protein, a molecule that competes with HTf for binding to TfR1. In contrast, TfR2 has lower affinity for HTf; its levels are not modulated by IREs (West et al., 2000) and, although still controversial, seems to bind HFE protein in a sequence non-overlapping to that of the Tf-binding site (for a review see Worthen and Enns, 2014).

The TfR2 is present in two main isoforms, TfR $2 \alpha$ and TfR $2 \beta$. The TfR2 $\alpha$ form has been reported to be more abundant in the brain, especially in the hippocampus; brain TfR $2 \alpha$ levels were reported to significantly differ across animals fed iron-deficient or iron-enriched diets (Pellegrino et al., 2016). A specific role for TfR2 in the control of the iron regulatory network in the brain tissue has been recently suggested, as altered brain IRPs, iron accumulation, and reactive microglia signaling were found in TfR2-KO mice (Pellegrino et al., 2016). In contrast, a previous study on TfR2 mutant mice showed changes in hepatic, but not brain iron levels, although that study reported a 30\% increase in brain FT levels (Acikyol et al., 2013).

In addition to TfR 1 and TfR2, the multifunctional molecule GAPDH has been reported to work as a TfR in different cell types (Raje et al., 2007; Kumar et al., 2012) with a role in iron uptake and/or iron export (Sheokand et al., 2016) and as a chaperone for intracellular heme traffic (Sweeny et al., 2018). Relevant to brain and excitotoxicity, GAPDH interacts with the $\alpha$-amino-3-hydroxy-5-methyl-4-isoxazolepropionic acid subtype of glutamate receptors in the neurons without glutamate stimulation and has also been reported to be pivotal for axon development (Lee et al., 2016).

Another receptor-mediated means to import iron into brain cells, at least in oligodendrocytes, is the uptake of FTH through TIM-1/2 receptors (Todorich et al., 2008, 2011; Chiou et al., 2018a). In other non-neuronal cells, FTH internalize through TfR1 (Li et al., 2010), whereas scavenger receptor class A member 5 (SCARA5) has been found to play also a role as a receptor for FT light chain uptake (Li et al., 2009). To the best of our knowledge, the role of SCARA5 has not yet been investigated in any brain cell type.

\section{Mechanisms and Proteins Involved in Cytosolic Iron Handling in Different Brain Cell Types}

Inside the cell cytosolic and nuclear compartments, iron chaperone poly(rC)-binding proteins serve the binding and delivery of iron to iron-requiring enzymes, ubiquitous protein of iron storage FT, or the iron export membrane protein FPN (Philpott et al., 2017). In the cytosol, unused iron is stored into FT, a molecule composed of 24 subunits of a variable proportion of heavy and light chains, that shields up to 4500 iron atoms in a redox inert state. Neurons express both TfR1 and DMT1 (Pelizzoni et al., 2012; DeGregorio-Rocasolano et al., 2018); DMT1 is mainly found in the cytoplasm colocalizing with endosomes/lysosomes. Further, neurons express the iron export molecule FPN (Burdo et al., 2001; Zhou et al., 2017). Astrocytes express TfR1, DMT1, and FPN (Yang et al., 2012; Huang et al., 2014). Hence, although TfR1 is considered to be the main gate for cellular iron import, control astrocytes show low TfR1 levels, and most mature oligodendrocytes or microglial cells do not express TfR1 (Kaur and Ling, 1995; Rathnasamy et al., 2016). However, under hypoxia, both astrocytes and oligodendrocytes are found to upregulate TfR (Yang et al., 2012; Rathnasamy et al., 2016). Moreover, oligodendrocytes and cells of choroid plexuses, but not other brain cell types, express Tf under normal condition (Leitner and Connor, 2012). All the above are examples of the important heterogeneity in the expression and induction of iron homeostatic or IRPs observed in different brain cell types and situations. Most of the proteins involved in iron metabolism, including cytosolic FT levels, are mainly regulated by iron, oxidative stress, and inflammation. The irondependent regulation occurs mainly at the post-transcriptional level via the IREs and iron regulatory protein (IRP) machinery. When iron levels are high, iron binds to the IRP, which then loses affinity for the IRE sequence in FT mRNA, resulting in increased FT expression (the cytosolic iron handling is depicted in Figure 2) (Arosio et al., 2017). Several studies have shown that the mobilization of iron from FT requires FT degradation either by lysosome-autophagy or ubiquitin proteasome pathways (Asano et al., 2011; Mancias et al., 2015). In addition to its role in storing iron within the cell, FT can be secreted (TrumanRosentsvit et al., 2018).

In addition to post-transcriptional regulation, transcriptional regulation has been reported for some of the proteins involved in iron homeostasis through the hypoxia-inducible factor family of transcription factors or the heme-dependent transcription factors (e.g., for TfR1 or FPN) (Marro et al., 2010; Man-man et al., 2017). Moreover, the master regulator of bodily iron homeostasis hepcidin is subjected to a sophisticated transcriptional regulation through the bone morphogenetic protein/SMAD pathway, interleukin 6 pathway, or erythropoietin/erythroferrone pathways when regulated according to the iron, inflammatory, or erythropoietic demands (Sangkhae and Nemeth, 2017). The regulation of cellular iron balance has been recently reviewed (Recalcati et al., 2017).

Iron also plays an important role in specific organelles; this is especially true for mitochondria. Mitochondria house the assembly of heme, the majority of the Fe-S cluster biosynthesis apparatus, and contain the respiratory complexes that need ironcontaining cofactors. In addition, mitochondria are a major source of endogenous ROS. Sustained iron exposure increased mitochondrial ROS levels in dopaminergic neuroblastoma SHSY5Y cells (Huang et al., 2017), and scavenging of mitochondrial ROS was protective against iron overload damage in hippocampal neurons, preserving mitochondrial morphological integrity and membrane potential (Pelizzoni et al., 2011). In addition, a recent study showed that sequestration of iron by mitochondrial FT was neuroprotective against oxidative stress and played an important role in preventing neuronal damage in some other conditions (You et al., 2016; Guan et al., 2017). Moreover, mitochondrial FT overexpression significantly reduced cellular labile iron pool, 
prevented $\mathrm{H}_{2} \mathrm{O}_{2}$-induced elevation of labile iron, and rescued cells from $\mathrm{H}_{2} \mathrm{O}_{2}$-induced damage (Gao et al., 2017).

In several cell types, although not yet studied in neurons, mitochondria-endosome interactions have been observed, suggesting a possible direct transfer of iron from endosomes to mitochondria (Das et al., 2016; Hamdi et al., 2016) through the "kiss-and-run" hypothesis.

\section{IRON DYSHOMEOSTASIS IN THE BRAIN}

Brain iron abnormalities are associated to rare, but severe, neurodegenerative conditions, and there is growing evidence that the more common systemic iron overload disorders such as hereditary hemochromatosis exert important effects on the brain iron content and pathological brain iron deposition (Nandar and Connor, 2011; Kumar et al., 2016). Moreover, the hemochromatosis H63D polymorphism of the HFE gene could be a disease-modifying gene in frontotemporal lobar degeneration, fostering iron deposition in the basal ganglia (Gazzina et al., 2016), or even macro- and microanatomically altering some brain structures associated with changes in Tf levels in the blood (Jahanshad et al., 2012). Recently, abnormal recycling of TfR1 due to reduced post-translational palmitoylation has been reported to be crucial to affect the iron import in the socalled neurodegeneration with brain iron accumulation disease (Drecourt et al., 2018). Further, neurodegeneration with brain iron accumulation disease-linked genes that showed altered expression in response to iron loading has been recently reported to be directly or indirectly related to myelin metabolism (Heidari et al., 2016).

A list of mild conditions, including aging (Ward et al., 2014), continuous uptake of some bioavailable iron sources (Peters et al., 2018), or obesity (Han et al., 2017), have been reported to alter brain iron content and/or distribution. In addition, a recent report showed that iron administration increases iron levels in the brains of healthy rats, which induces brain changes and triggers a hormetic response that reduces oxidative damage (Piloni et al., 2018). Moreover, other studies reveal a complex interplay between inflammation and brain iron homeostasis (Righy et al., 2018; Sankar et al., 2018), with acute inflammation increasing non-Tf iron uptake by brain microglia (McCarthy et al., 2018). This dyshomeostasis is especially important in acute pathologies such as stroke, in which the impairment of the BBB regulatory role is rapidly and massively affected following either rupture of an artery (ICH) or aberrant increase of brain microvascular endothelial permeability following ischemic stroke (AIS). Dysregulation of iron resulting in the accumulation of free iron and brain iron overload, which can increase the production of ROS, is evident in aging and stroke-related pathologies and is also a hallmark of chronic and long-term neurodegenerative pathologies. In this regard, iron overload in the brain has been reported in Huntington, Parkinson, or Alzheimer diseases [readers interested in the topic are referred to recent detailed reviews by Morris et al. (2018) and Uranga and Salvador (2018)]. Interestingly, marked age-related changes in brain iron homeostasis have also been observed in amyloid precursor protein (APP)-knockout mice (Belaidi et al., 2018).

\section{IRON OVERLOAD WORSENS NEUROLOGICAL DAMAGE BOTH IN ISCHEMIC STROKE AND INTRACEREBRAL HEMORRHAGE}

Stroke is a life-threatening disease that causes high rates of permanent disability subsequent to neuronal loss. There are two major types of strokes: ischemic stroke or AIS, which is caused by a blood clot blocking an artery and accounts for $85 \%$ of all strokes, and hemorrhagic stroke or ICH, caused by leakage or rupture of an artery and accounts for $15 \%$ of stroke cases.

\section{Iron Overload Condition in Stroke Damage and Outcome}

In ischemic stroke, neurons die because of interrelated processes that include glutamate excitotoxicity, excess of free radical production, and inflammation (Nagy and Nardai, 2017). Each of these mechanisms has already been targeted in clinical trials, although unsuccessfully (for a review see Chamorro et al., 2016). Moreover, free radical-induced oxidative stress has been for long recognized as a pathogenic factor in the ischemia/reperfusion (I/R) injury that follows reoxygenation. The hydroxyl radical, the most harmful of the free radicals, is generated through reactions catalyzed by iron (Kell, 2009; Chen H. et al., 2011). Of relevance to stroke damage and final outcome, several clinical studies indicate that a previous systemic iron overload condition, measured as high levels of serum FT at admission, is associated with increased brain damage and worse outcome induced by ischemic stroke (Davalos et al., 1994; Millan et al., 2007). A similar detrimental effect (increased ischemic damage) was observed in iron-overloaded animals exposed to experimental ischemic stroke (Castellanos et al., 2002; Gamez et al., 2003; Mehta et al., 2004; García-Yébenes et al., 2012; DeGregorioRocasolano et al., 2018). Iron overload is a major source of oxidative stress in ischemic brains (Carbonell and Rama, 2007). In addition, iron overload exacerbated the risk of hemorrhagic transformation in animal models of transient ischemia plus early reperfusion (García-Yébenes et al., 2012; García-Yébenes et al., 2018); therefore, in iron-overloaded animals, an initial ischemic event has higher probability to become an ICH. The contribution of iron overload to widespread the damage in the ICH is supported by the fact that systemic iron overload (estimated using high serum FT levels) was associated with higher perihematoma edema and poor outcomes in patients with ICH (Mehdiratta et al., 2008; Perez de la Ossa et al., 2010; Bakhshayesh et al., 2014; Garton et al., 2017). Further, a combination of high serum FT and low serum iron and Tf was associated with poor outcome in ICH patients (Yang et al., 2016). Therefore, systemic iron overload impacts the outcome of both ischemic and hemorrhagic stroke patients.

The brain is physiologically sheltered from fluctuations in systemic iron because of the BBB, even under experimentally 
induced diet iron overload conditions or intraperitoneal iron administration (Castellanos et al., 2002; Millerot et al., 2005). However, in the ischemic brain, the detrimental effect of iron overload might result from systemic iron pools reaching the brain parenchyma. Following artery occlusion, a physiological increase in transport through a still somehow intact BBB is noted, and thereafter pathological halt of the BBB function that results in leaky or broken capillaries that allow blood spill out (Figure 1). Some BBB impairment with aberrant exchange of brain and blood molecules occurs relatively early following ischemic stroke (within the first hours of post-symptom onset) showing a biphasic behavior in some studies (Klohs et al., 2009). Moreover, leakage through the BBB varies in different experimental stroke models (Klohs et al., 2009; Abulrob et al., 2011). Of note, post-stroke BBB leakage also varies in different areas of the brain, whereas the administration of the broadly used thrombolytic agent tissue plasminogen activator increases leakage (Jaffer et al., 2013), resulting in hemorrhagic transformation. Moreover, a recent evidence of the pivotal contribution of BBB leakage to ischemic stroke damage has been revealed by a study in which a vascular leakage blocker reduced stroke damage (Zhang et al., 2017).

\section{Effect of Stroke on Brain Iron}

Regarding iron content of the brain following ischemic stroke, an increase in total iron was observed in the ischemic areas after permanent or transient ischemic stroke (Helal, 2008; MillerotSerrurot et al., 2008; Tuo et al., 2017). In addition, increased TfR and iron levels were observed in susceptible hippocampal areas following transient global cerebral ischemia (Park et al., 2011), or increased extravasation of iron-loaded HTf was observed following acute focal ischemic stroke (DeGregorio-Rocasolano et al., 2018). In fact, HTf from blood accumulates in the brain parenchyma of the rat ischemic brain hemisphere at $1 \mathrm{~h}$ after reperfusion (DeGregorio-Rocasolano et al., 2018). Subsequently, iron accumulates into the endothelial cells of brain capillaries near ischemic areas (Desestret et al., 2009), whereas increased levels of Tf were observed $24 \mathrm{~h}$ following a transient experimental stroke at the ischemic hemisphere (Lo et al., 2007). In fact, this Tf seems to accumulate in neurons since Tf immunoreactivity was found located at the neuronal cytoplasm $24 \mathrm{~h}$ after stroke onset (DeGregorio-Rocasolano et al., 2018).

In the ICH stroke type, the systemic iron pools play a direct role in brain damage since the rupture of the microvascular wall and concomitant blood release results in neurons, astrocytes, and other cells around the hemorrhagic area to become immediately exposed to blood-derived iron, either free or bound to $\mathrm{Tf}$ (Figures 1, 2). Moreover, the brain is exposed to a bulk amount of erythrocytes that undergo lysis and subsequent spill of hemoglobin (Hb). Erythrocyte lysis occurs within minutes and continues for days after the formation of brain hematoma, leading to the release of red blood cell-derived products. Cells of the brain are then sequentially exposed to aberrantly high extracellular levels of $\mathrm{Hb}$, the oxidized $\mathrm{Hb}$ form methemoglobin, and free heme or the iron ferric heme form hemin. The main mechanisms of neurodegeneration in hemorrhagic stroke are iron- and heme-induced ROS production, amplification of an inflammatory response, direct toxic effects of iron and heme, and glutamate-induced excitotoxicity (Righy et al., 2016).

\section{BRAIN REGULATION OF IRON METABOLISM DURING STROKE}

\section{Endogenous Mechanisms Involved in the Protection of Brain Cells From Excess Iron Following AIS}

Increased brain Tf or TfR1 levels (Ding et al., 2011; DeGregorioRocasolano et al., 2018) were observed in lethal ischemia. Consensus exists about the protective role of increased FT expression during experimental stroke, and the same applies to hepcidin in AIS; however, the role of blunting the ischemia-induced upregulation of $\mathrm{Tf}$ and $\mathrm{TfR}$ remains controversial. Reductions of Tf and TfR were considered to be associated with neuroprotection in one specific stroke model (Lo et al., 2007). However, other neuroprotective conditions were not associated with Tf and/or TfR reductions (He et al., 2012).

Hepcidin seems to protect from neurodegeneration in AIS. It is an iron-inducible peptide hormone that is considered to be the main regulator of iron homeostasis. Hepcidin is produced as a propeptide mainly in the liver and then secreted to the blood where it interacts with the only known iron exporter FPN located at the cell membrane. Hepcidin acts as a negative regulator of cellular iron release by binding FPN and causing its internalization and degradation; this inhibits FPN-mediated iron egression from enterocytes, macrophages, hepatocytes and, as recently found, some other cell types (e.g., endothelial cells or neurons). The inhibition of iron egression, mainly from macrophages and hepatocytes, prevents the presence of NTBI in the blood as well as reduces the TSAT in the blood. In line with its main function, hepcidin deficiency leads to iron overload (Nicolas et al., 2001), and hepcidin overexpression causes severe iron deficiency (Nicolas et al., 2002a). Hepcidin has a rapid and direct impact on circulating iron pools. In fact, even a single intraperitoneal administration of hepcidin reduces the TSAT in blood to less than half the normal levels for 6-12 h (Sillerova et al., 2012). Both blood hepcidin and HTf/apotransferrin ratio might be considered as the master regulatory factors of systemic iron metabolism, since hepcidin senses iron by sensing HTf levels in the circulation and iron-FT levels inside hepatocytes. Relevant to this review on iron and stroke, hepcidin expression is also responsive to hypoxia (Nicolas et al., 2002b; Sonnweber et al., 2014) mainly by the oxygen-regulated hypoxia-inducible factor. In general, hypoxia inhibits hepcidin expression to allow the mobilization of iron to sustain erythropoietic expansion. However, a recent study showed that the exposure of mice to an hypoxic environment induces biphasic modulation of hepcidin expression with a transient increase in liver expression within the first $6 \mathrm{~h}$ and a reduction after $15 \mathrm{~h}$ of hypoxia (Ravasi et al., 2018).

Among ischemic stroke patients, who have areas of the brain exposed to oxygen and glucose deprivation (OGD), blood hepcidin levels increased within the first $6 \mathrm{~h}$ from symptom onset compared to those in controls; serum hepcidin levels in 
ICH patients were similar to those of controls (unpublished results from our laboratory). This early increase in blood hepcidin during ischemic stroke is in agreement with the early increase reported in the hypoxic mice model (Ravasi et al., 2018) and with the two other reports on stroke patients (Petrova et al., 2015; Slomka et al., 2015) and might be a reflection of an increased expression and secretion of hepcidin from the ischemic brain cells to the extracellular medium, and a subsequent spillover out of the brain during stroke. Although hepcidin expression in the brain is thought to be low in basal conditions, hepcidin is now emerging as an important player in brain iron homeostasis (Vela, 2018). Hepcidin mRNA levels increased early in the brain in response to ischemia in a model of endothelin-induced vasoconstriction (Bickford et al., 2014), and hepcidin levels were significantly elevated in the ischemic side of the brain $24 \mathrm{~h}$ after occlusion in a stroke model due to middle cerebral artery occlusion; this ischemic side also showed increased TfR 1 and FT levels and reduced FPN levels (Ding et al., 2011). In addition, knock-down of hepcidin slows the ischemicmediated changes in brain FT and FPN, revealing an important contribution of this molecule to parenchyma iron regulation in cerebral ischemia. Further, normoxic iron-overloaded rats, hepcidin, either overexpressed in the brain or administrated to the brain parenchyma, reduced brain uptake of iron in vivo as well as reduced iron uptake in cultures of neurons or brain microvascular endothelial cells, owing to the dowregulation of iron-transport proteins (Du et al., 2015). In microglial cells, the bone morphogenetic protein antagonist noggin abrogated the OGD-induced changes in hepcidin, FPN, and FT levels, and this inhibition of bone morphogenetic protein/hepcidin axis in vitro shifted reactive microglia from an iron-storing to an iron-releasing phenotype after OGD plus reperfusion (Shin et al., 2018). Factors released from noggin- and OGD-exposed microglial culture medium were found to increase myelin production in oligodendrocyte cell cultures; since this effect is blunted by the iron chelator deferoxamine (DFO), iron released from the microglia is proposed to serve in the remyelination in the ischemic brain (Shin et al., 2018).

\section{Endogenous Mechanisms Involved in the Protection of Brain Cells From Excess Iron Following ICH}

Similar to that observed in AIS, subarachnoid hemorrhage has been shown to increase hepcidin expression in neurons (Zhao et al., 2018) associated with a reduction of its downstream target FPN (Tan et al., 2016). However, in this hemorrhage model, hepcidin seems to be harmful since its administration potentiated and its siRNA decreased apoptosis and early brain damage (Tan et al., 2016). In agreement with a harmful effect of hepcidin on brain hemorrhage, higher blood hepcidin levels were observed 1-7 days following ICH in patients with poorer outcomes (Xiong et al., 2015). The rationale for this harmful effect of hepcidin following ICH might be an impaired clearance of iron from brain parenchyma, since increased hepcidin expression caused by inflammation was found to inhibit intracellular iron efflux from brain microvascular endothelial cells and further draining of iron into circulation, leading to the aggravation of oxidative brain injury (Xiong et al., 2016). Conversely, addition of hepcidin or adenovirusdriven overexpression of hepcidin has been shown to protect neurons from hemin-induced injury (Zhou et al., 2017); this protection was thought to be related to the effect of hepcidin reducing hemin-induced iron uptake and reduced expression of TfR1 and DMT1.

Moreover, importantly, stroke has an inflammatory component, and some inflammatory inducers or mediators (e.g., lipopolysaccharide or interleukin 6) have been found to increase the expression of hepcidin in astrocytes, microglia, or neurons (for a recent review see Vela, 2018), although the effect on neurons is usually weaker (Ma et al., 2018).

The brain has protective mechanisms that can be activated after ICH and erythrocyte lysis, the most important one being the $\mathrm{Hb}$-scavenging molecule haptoglobin $(\mathrm{Hp})$ and the hemescavenging system hemopexin ( $\mathrm{Hpx}$ ) (Figure 2). $\mathrm{Hb}$ itself is avidly bound by $\mathrm{Hp}$ to form a complex that prevents the release of the heme group from $\mathrm{Hb}$ or methemoglobin. However, $\mathrm{Hp}$ cannot prevent the release of the heme group from the highest oxidative $\mathrm{Hb}$ form ferryl $\mathrm{Hb}$. In the brain, $\mathrm{Hp}$ is almost exclusively synthesized by oligodendrocytes, and mice overexpressing $\mathrm{Hp}$ were more resistant, whereas Hp-knockout mice were more susceptible, to ICH injury (Zhao et al., 2011). The complex $\mathrm{Hp}: \mathrm{Hb}$ binds to the Hp-specific receptor $\mathrm{CD} 163$ that is present in macrophages, allowing them to remove $\mathrm{Hb}$ from the extracellular space. In addition, CD163 is upregulated in neurons after ICH (Liu et al., 2017). The role of $\mathrm{Hp}$ in neuroprotection was not devoid of controversy since $\mathrm{Hp}$ was found to exacerbate the vulnerability of $\mathrm{CD} 163$-expressing neurons to $\mathrm{Hb}$, an effect that was reduced by iron chelators (Chen-Roetling and Regan, 2016). However, most $\mathrm{Hb}$ was not bound to $\mathrm{Hp}$, indicating that the $\mathrm{CD} 163-\mathrm{Hb}-\mathrm{Hp}$ system is saturated, and that the primary route for $\mathrm{Hb}$ clearance from the CNS occurs through the BBB (Galea et al., 2012; Righy et al., 2018). A good clearance is associated with neuroprotection since lower CSF Hp levels were found in ICH patients without clinical and/or radiological evidence of delayed cerebral ischemia (Galea et al., 2012). Hb accumulated in the brain parenchyma is converted to ferrylHb, which causes the upregulation of proinflammatory adhesion molecules and increases the recruitment of inflammatory neutrophils or macrophages (Jeney et al., 2013).

Iron-hemin uptake has been reported in neurons and astrocytes and is especially high in microglial cell cultures; neurons benefit from a high export of iron following the initial iron-hemin loading, and this export was exacerbated by treatment with $\mathrm{DFO}$, a compound that attenuates hemin neurotoxicity (Chen-Roetling et al., 2014). As already mentioned, the brain produces the heme scavenger protein Hpx that protects from deleterious effects of heme. In this regard, deletion/knockout of the Hpx aggravates brain injury by ICH (Chen L. et al., 2011; Ma et al., 2016) and, although endogenous levels of Hpx are insufficient to counteract the massive heme overload following $\mathrm{ICH}$, increasing brain Hpx levels has been found to improve the outcome after ICH (Leclerc et al., 2018). Conversely, Hpx has recently been reported to increase the 
neurotoxicity of $\mathrm{Hb}$ in the absence of $\mathrm{Hp}$ (Chen-Roetling et al., 2018). Therefore, although both $\mathrm{Hp}$ and Hpx might provide a robust line of defense during $\mathrm{ICH}$, additional knowledge on the fine tuning of this system is still required to design new possible neuroprotective treatments for ICH. The low-density lipoprotein receptor-related protein CD91 is expressed in several cell types, including macrophages and neurons, and was identified as the Hpx-heme receptor, mediating Hpx-heme uptake by endocytosis (Hvidberg et al., 2005). Once inside the cell, the heme oxygenase (HO) system is responsible for cellular heme degradation. In neurons, $\mathrm{HO}$ generates biliverdin, which has been reported to scavenge free radicals. Astrocytes rapidly upregulate $\mathrm{HO} 1$ and FT and are resistant to heme-mediated injury, and astrocyte $\mathrm{HO} 1$ is known to play a robust neuroprotective role after hemorrhage (Chen-Roetling et al., 2017). A recent study indicated that Hpx activates endothelial progenitor cells and reduces synaptic damage in a rodent ischemic stroke model; these effects require HO1 activity (Yang et al., 2018).

Moreover, the presence of heme groups in the extracellular milieu activates the endothelial expression of adhesion molecules and promotes the activation of neutrophil extracellular traps through a mechanism dependent on ROS generation (Chen et al., 2014). Further, inflammatory response is a well-documented mechanism of brain damage after ICH (Wang and Doré, 2007), and the mechanisms underlying heme-induced inflammation have been reviewed elsewhere (Dutra and Bozza, 2014). Iron and heme associated with pro-inflammatory mediators in the CNS following hemorrhagic stroke and inflammatory profiles are associated with poorer prognosis. Similarly, iron-induced damage following ischemic stroke in iron-overloaded animals has also been related to increased inflammatory responses associated with increased serum levels of interleukin 6 and TNF-alpha (Castellanos et al., 2002).

\section{THE FERROPTOTIC COMPONENT OF STROKE-INDUCED NEURODEGENERATION}

\section{The Concept of Ferroptosis: Molecular Players Involved in Ferroptosis in the Neurons}

The concept of ferroptosis was introduced as a form of cell death, which is morphologically, biochemically, and genetically distinct from apoptosis, necrosis, and autophagy; it is associated with excessive iron-mediated accumulation of lipid ROS in cancer cells as well as in hippocampal slice cultures exposed to glutamate excitotoxicity (Dixon et al., 2012). As excitotoxicity is the main mechanism involved in neuronal death in ischemic stroke, the involvement of ferroptosis in ischemic stroke could be suspected. In addition, the role of high systemic iron exacerbating stroke-induced damage, concomitant with increased brain iron after ischemic stroke onset (reviewed in the previous section), further suggested a possible ferroptosis component in stroke; in the recent past, mounting evidence indicated that ferroptosis plays such a pivotal role in stroke-induced neurodegeneration in both ischemic and hemorrhagic stroke subtypes. Although the concept is still evolving, ferroptosis is now considered a unique form of regulated cell death characterized by cytosolic accumulation of iron and executed by the massive peroxidation of PUFA in the plasma membrane and associated with reduced glutathione (GSH). Compounds that induce only either cytosolic or mitochondrial ROS production are not considered as ferroptosis inducers. A recent study proposed that both Fenton reactions, in which $\mathrm{Fe}^{2+}$ converts to $\mathrm{Fe}^{3+}$ producing ROS, and enzymatic lipoxygenase-mediated reactions in cellular membranes contribute to ferroptosis (Feng and Stockwell, 2018). Some authors considered that the ferroptosis concept and the previously described oxidative oxytosis concept have many common features to be regarded as independent processes (Lewerenz et al., 2018). In fact, the widely used oxidative stress stimulus tert-butylhydroperoxide was found to induce neuronal cell death that was blocked by ferroptosis inhibitors, thereby implying a crosstalk between the initial oxidative damage and the occurrence of ferroptosis (Wu et al., 2018). However, ferroptosis is considered a major driver of cell death in many neurodegenerative and neurological diseases (Lewerenz et al., 2018; Morris et al., 2018).

Ferroptosis can be triggered by the inhibitors of the lipid repair enzyme glutathione peroxidase 4 (GPX4), such as the RAS-selective lethal 3 compound, or depletion of the antioxidant GSH by starving the cells of GSH precursors [inhibiting the cystine/glutamate antiporter, i.e., system $\mathrm{X}_{\mathrm{c}}^{-}\left(\mathrm{X}_{\mathrm{c}}^{-}\right)$with erastin, sulfasalazine, sorafenib, or, alternatively, challenging the exchange capacity of $\mathrm{X}_{\mathrm{c}}^{-}$with high extracellular glutamate]. Extracellular Tf in its iron-loaded HTf form is considered as an inducer of ferroptosis as well, and inhibiting TfR expression prevents ferroptosis (Gao et al., 2015).

At present, the existence of $\mathrm{X}_{\mathrm{c}}^{-}$in neurons is still controversial, with one report showing expression lack of $\mathrm{X}_{\mathrm{c}}^{-}$in neurons (Ottestad-Hansen et al., 2018), whereas another showing neurons expressing significant $X_{c}^{-}$levels (Soria et al., 2016). However, neurons in culture overexpress $\mathrm{X}_{c}^{-}$shortly after being exposed to OGD (Soria et al., 2014). The physiological role of $\mathrm{X}_{\mathrm{c}}^{-}$as a cystine importer is linked to its antiporter glutamate export and requires that extracellular levels of glutamate and other excitatory amino acids are maintained low by the action of excitatory amino acid transporters (EAATs). Thus, one of these glutamate transporters, the sodium-dependent EAAT3, might be selectively expressed in neurons and could also be an unidirectional cysteine import channel, with extracellular glutamate inhibiting its cysteine import capacity (Watts et al., 2014). EAAT3 might be as important as $\mathrm{X}_{\mathrm{c}}^{-}$in providing GSH precursors to neurons, considering that mice lacking EAAT3 have lower GSH levels and age prematurely (Aoyama et al., 2006). Notably, low GSH levels might also inhibit GPX4 activity since GPX4 uses GSH as a cofactor to catalyze the reduction of lipid peroxides and protect cells membranes against peroxidation (see Latunde-Dada, 2017).

Conversely, ferroptosis can be prevented by (1) ironbinding compounds such as DFO and ciclopirox; (2) small molecules, free radical scavengers, or lipophilic antioxidants such as ferrostatin-1, $\alpha$-tocopherol, butylated hydroxytoluene, or liproxstatin-1; (3) treatments with molecules such as deuterated 
PUFA, inhibitors of acyl-CoA synthetase long-chain family member 4, lipoxygenase inhibitors, glutaminolysis inhibitors, or cycloheximide; or (4) boosting cystine and/or cysteine import by reducing extracellular glutamate.

Glutamate is the most abundant excitatory neurotransmitters in the vertebrate nervous system, with $90 \%$ of the synaptic neurotransmission considered glutamatergic (Hofmeijer and Van Putten, 2012; Mayor and Tymianski, 2018). Under physiological conditions, extracellular glutamate levels are low, and glutamate exerts its physiological role mainly at the neuronal synapse. The ability of astrocytes near glutamatergic neurons to rapidly clear synaptic glutamate after its physiological action is critical in the functioning of synapses and neuronal circuits, and the initial increase of extracellular glutamate is inhibited mainly by glial EAAT1 and 2. Neuronal glutamate transporters, mainly EAAT3, also play a role in clearing extracellular glutamate excess. However, ischemia leads to energy failure and subsequent electrochemical gradient impairment, causing EAATs to act in a reversed manner, thereby extruding nonvesicular intracellular glutamate and resulting in large excess of extracellular glutamate and impairment of EAAT3 as a unidirectional cysteine import channel.

The impact of excess extracellular glutamate on neuronal survival is more than that on the cystine/glutamate exchanger $\mathrm{X}_{\mathrm{c}}^{-}$. In fact, most of the effect is produced by glutamate binding to specific glutamate receptors present in cell membranes of several cell types and, especially in neurons, $\mathrm{N}$-methyl-D-aspartate (NMDA) subtype of glutamate receptors (NMDARs) (Guirao et al., 2017) that are coupled to an intracellular downstream complex of signaling effectors, which are known to initiate excitotoxic neuronal death following ischemia.

Although both glutamate and iron are essential for neuronal survival, excess glutamate can be toxic, and excess free iron through the Fenton reaction is a potentially toxic substance that can catalyze the production of extremely damaging ROS. During stroke, the impairment of $\mathrm{BBB}$ function allows increased access to brain of iron-carrying substances and, preceding neurodegeneration, iron accumulates in the ischemic areas (Helal, 2008); therefore, not surprisingly, iron overload conditions are associated with larger areas of brain damage in animals exposed to experimental ischemic stroke (Castellanos et al., 2002; Gamez et al., 2003; Mehta et al., 2004; GarcíaYébenes et al., 2012; DeGregorio-Rocasolano et al., 2018). Following experimental stroke or NMDAR overactivation, prevention of NMDA-induced neuronal iron uptake was found to be neuroprotective (DeGregorio-Rocasolano et al., 2018). Therefore, the crosstalk between neuronal homeostasis of iron and glutamatergic signaling is increasingly being supported by evidence and should not be disregarded as a therapeutic intervention target.

\section{Glutamate-Induced Iron Uptake in Neurons and Ferroptosis}

Cheah et al. (2006) from Dr. Snyder's laboratory published a study before the concept of ferroptosis was introduced and showed that the overactivation of NMDAR in neurons induces, in addition to the well-known NMDAR-mediated calcium influx, an NMDAR-mediated iron uptake. They also identified a signaling cascade whereby NMDAR regulated neuronal iron homeostasis and excitotoxicity through an NMDAR/nitric oxide/dexamethasone-induced Ras protein 1 (Dexras1) pathway that increased both non-Tf and Tf-mediated iron uptake from the extracellular medium through the neuronal plasma membrane (Cheah et al., 2006). A similar increase of iron uptake in hippocampal neurons was observed in a subsequent study in which either synaptic activity or NMDAR activity was boosted (Pelizzoni et al., 2011). Moreover, either ischemia or NMDA overactivation increased the uptake of HTf, resulting in an increase of cytosolic redox-active iron in neurons, whereas blockade of TfR1 reduced iron dyshomeostasis and NMDAinduced excitotoxicity (DeGregorio-Rocasolano et al., 2018). The original work from Snyder's laboratory hypothesized that iron in its free form gains access to the neuronal cytosol through DMT1 present in the neuronal membrane. However, this would not explain the uptake of Tf-bound iron since the DMT1 isoform endogenously overexpressed in primary cultures of hippocampal neurons exposed to NMDA is DMT1-1B/IRE(+) (Haeger et al., 2010) and is found in endosomes/lysosomes in the cytoplasm (Pelizzoni et al., 2012), thereby not supporting a direct role of DMT1 in iron entry through the neuronal membrane. Following the above rationale of crossroads between excitotoxicity and ferroptosis, several in vitro and in vivo studies showed that neurons survive otherwise lethal NMDA or glutamate concentrations when treated with iron chelators such as DFO or deferasirox ( $\mathrm{Yu}$ et al., 2009; Tian et al., 2017; Sakamoto et al., 2018). Moreover, a study showed that the deletion of Dexras1 reduced NMDA-induced iron uptake and NMDA toxicity in cortical neurons and retinal ganglion cells (Chen et al., 2013). Moreover, Dexras1-KO mice showed increased expression of the NR2A subunit of the NMDAR (Carlson et al., 2016), a subunit that is preferentially located at synapses and related to NMDAR pro-survival signaling; this strongly suggests the existence of a functional crosstalk between the NMDA-induced iron intracellular signaling and the physiological NMDAR function. Interestingly, intracellular iron released from lysosomes has been shown to modulate NMDAR synaptic excitability via Dexras1 (White et al., 2016), and iron is needed post-synaptically to activate $\mathrm{Ca}^{2+}$-dependent pathways downstream NMDAR (Muñoz et al., 2011). Further, glutamateinduced neuronal excitotoxicity was described as ferroptosis (Dixon et al., 2012).

In the widely reported scenario of elevated extracellular glutamate during ischemic stroke, NMDAR-induced iron import was upregulated in neurons associated with increased ROS production (Cheah et al., 2006), and system $\mathrm{X}_{\mathrm{c}}^{-}$and EAAT3 cystine/cysteine import are impaired by high extracellular glutamate (Conrad and Sato, 2012), thus compromising neuronal iron homeostasis and GSH-mediated free radical detoxification, eventually leading to an excess lipid oxidative stress that causes ferroptotic damage. High GSH stores are pivotal for cell survival since GSH is required for GPX4 activity and is also thought to be the only molecular species having a significant role as a cytosolic ligand for $\mathrm{Fe}^{2+}$ (Philpott and 
Ryu, 2014). Even when ischemia is resolved in the brain owing to a successful reperfusion, other mechanisms involved in ferroptotic damage might become dangerous. In this regard, a recent study on Sertoli cells revealed that GPX4 is inactivated via GSH depletion following I/R injury (Li et al., 2018), and several studies showed that GPX4 gene inactivation causes hippocampal neurodegeneration (Seiler et al., 2008; Hambright et al., 2017) and a remarkable degeneration of motor neurons (Chen et al., 2015).

\section{Ferroptosis in AIS and ICH Stroke Subtypes: Effect of Ferroptosis Inhibitors and Iron Chelators}

In addition to a pivotal role of ferroptosis in I/R-induced damage in several peripheral organs (Friedmann Angeli et al., 2014; Linkermann et al., 2014; Gao et al., 2015), a role of ferroptosis has been specifically identified in I/R-induced brain damage in transient ischemia, as brain damage was substantially reduced by the ferroptosis inhibitor liproxstatin-1 in an AIS model (Tuo et al., 2017). These authors also showed that a reduction of tau levels, a protein that facilitates iron export by trafficking APP to membranes to stabilize FPN, was found to precede a pro-ferroptotic iron accumulation in the brain following I/R (Tuo et al., 2017). APP mRNA possesses a functional IRE with sequence homology to that of FT, and its translation is responsive to free iron levels in the cytosol (Duce et al., 2010). In addition, APP has been reported to interact with FPN to promote iron release in several brain cell types (Duce et al., 2010; McCarthy et al., 2014). APP overexpression reduces free iron content in neuroblastoma cells (Wan et al., 2012), and either preventing APP transport to the cell surface or knocking down of APP results in iron accumulation in primary cortical neurons in culture (Lei et al., 2012). The complete role of APP in ferroptosis and neurodegeneration in AIS requires additional studies. However, further evidence supporting the involvement of ferroptosis mechanisms in AIS brain damage is provided by the overexpression of lipoxygenases following brain ischemia and the protection afforded by treatment with lipoxygenase inhibitors (Cui et al., 2010; Karatas et al., 2018). Further, a recent study showed that $\mathrm{N}$-acetylcysteine (NAC), an FDA-approved cysteine prodrug, prevents hemin-induced ferroptosis by neutralizing toxic lipids generated by arachidonate-dependent activity of 5lipoxygenases (ALOX5) (Karuppagounder et al., 2018). They reported that ALOX5 inhibitors such as zileuton and molecules such as NAC that inhibit toxic metabolic products of ALOX5 or prevent ALOX5 recruitment to its site of action, protect against hemin or $\mathrm{ICH}$-induced ferroptosis (Karuppagounder et al., 2018). Notably, NAC has been previously reported to prevent neuronal damage induced by AIS (Khan et al., 2004; Turkmen et al., 2016).

Further, the role of free iron in ferroptosis and neurodegeneration is further supported by the protective effect of treatments with exogenous iron chelators, e.g., DFO or 2,2'-dipyridyl, in animal models of stroke. After permanent ischemic stroke (Millerot-Serrurot et al., 2008), the increase in free iron, the iron form prone to induce lipid peroxidation and susceptible to be chelated, precedes the increase in total iron. In experimental models of transient ischemic stroke, DFO administered intramuscularly (Xing et al., 2009) or intranasally (Hanson et al., 2009) after the induction of ischemia significantly decreased infarct volume. Another iron chelator, the aforementioned 2,2'-dipyridyl was found to be cytoprotective after permanent arterial occlusion in rats; this was associated with reduced infarct size and preservation of GSH levels (Demougeot et al., 2004) or reduction of the apoptotic component and prevention of the enlargement of the lesion (Van Hoecke et al., 2005).

The role of iron in ICH neurodegeneration has been known for long. Recently, neuronal death following $\mathrm{ICH}$ was found to have features similar to those of ferroptosis, since chemical inhibitors of ferroptosis protected against $\mathrm{Hb}$ - and hemininduced neurotoxicity (Zille et al., 2017). The nonheme iron present in brain parenchyma after ICH is a source of redoxactive iron. The marked increase in brain nonheme iron was not cleared for weeks following the ICH event, and brain Tf, TfR, and FT levels were also increased $72 \mathrm{~h}$ after $\mathrm{ICH}$, thereby making FT upregulation long-lasting (Wu et al., 2003). Iron chelators such as DFO reduce hemin- and iron-mediated neurotoxicity, perihematoma edema, and neuronal damage, leading to good neurologic outcomes after ICH (Nakamura et al., 2004; Hatakeyama et al., 2013). Other recent studies indicated that the specific inhibitor of ferroptosis ferrostatin-1 reduces neuron degeneration and improves neurological deficit in experimental ICH models (Li Q. et al., 2017; Zhang et al., 2018), and GPX4 levels were found to be reduced after ICH, whereas pharmacological inhibition of GPX or genetic knockdown exacerbated brain injury after ICH (Zhang et al., 2018). Moreover, inhibitors of ALOX5 or inhibition of the ALOX5 metabolic products protected against hemin- or ICH-induced ferroptosis (Karuppagounder et al., 2018).

Moreover, DFO significantly reduced hemorrhagic transformation after focal I/R (Xing et al., 2009; Li Y. et al., 2017). Some studies have shown that the effect of DFO in preventing ischemic neuronal death is related to the DFOinduced expression of hypoxia-inducible factor 1 and its downstream targets genes rather than with its iron-chelating properties or, recently, with microglial/macrophage HO1 expression in ICH (LeBlanc et al., 2016). A systematic review and meta-analysis in experimental models of $\mathrm{ICH}$ showed that DFO was neuroprotective, e.g., reduction of brain edema and improvement of neurobehavioral outcomes, especially when it was administered $2-4 \mathrm{~h}$ after $\mathrm{ICH}$ induction (Cui et al., 2015). In clinical studies, conclusive evidence of the benefit of DFO treatment in ICH (Zeng et al., 2018) or AIS patients is still lacking; some clinical trials of DFO in ICH and AIS are currently ongoing.

The rationale for iron chelation as a neuroprotectant relies primarily on the idea that chelation removes free iron present in the blood and enhances iron elimination in the urine. After gaining access to other body compartments, DFO could also act by chelating free extracellular and cytosolic iron, whereas its effect on blood TSAT or blood total iron levels is modest (Tauchenová et al., 2016). In fact, DFO was shown to have 
an extremely slow removal rate of iron from Tf (Abergel and Raymond, 2008). This, together with the fact that DFO half-life in the plasma is extremely short $(20 \mathrm{~min})$, poses serious doubts about the effectiveness of the treatment with intravenous DFO unless administered with continuous infusion. Recently, another iron-regulator, apotransferrin, administered after stroke AIS onset, was found to be neuroprotective because of the systemic reduction of blood TSAT and a reduction of NMDA ischemia-induced neuronal iron import (DeGregorioRocasolano et al., 2018).

\section{CONCLUSION}

Increasing number of studies show that ferroptosis is involved in several neurodegenerative diseases. This review summarizes the knowledge available thus far regarding the role of iron and ferroptosis in the execution of neuronal cell death during AIS and ICH. In AIS-induced cell death, the role of systemic iron, Tf, TSAT, and hepcidin on excitotoxic damage, infarct size, and neurological outcome in rodent models of stroke might have important clinical implications. Following the AIS event, high levels of extracellular glutamate and impairment of the BBB allow the NMDAR-mediated influx of iron, either bound or not to Tf, into neurons. In addition, high extracellular glutamate prevents the neuronal production of the antioxidant GSH or the function of GPX4, thereby promoting a form of cell death in which glutamate receptor overactivation boosts neuronal iron uptake, which in turn promotes an overwhelming production of membrane peroxides. The role of iron in ICH neurodegeneration

\section{REFERENCES}

Abergel, R. J., and Raymond, K. N. (2008). Terephthalamide-containing ligands: fast removal of iron from transferrin. J. Biol. Inorg. Chem. 13, 229-240. doi: 10.1007/s00775-007-0314-y

Abulrob, A., Brunette, E., Slinn, J., Baumann, E., and Stanimirovic, D. (2011). In vivo optical imaging of ischemic blood-brain barrier disruption. Methods Mol. Biol. 763, 423-429. doi: 10.1007/978-1-61779-191-8_29

Acikyol, B., Graham, R. M., Trinder, D., House, M. J., Olynyk, J. K., Scott, R. J., et al. (2013). Brain transcriptome perturbations in the transferrin receptor 2 mutant mouse support the case for brain changes in iron loading disorders, including effects relating to long-term depression and long-term potentiation. Neuroscience 235, 119-128. doi: 10.1016/j.neuroscience.2013.01.014

Aoyama, K., Sang, W. S., Hamby, A. M., Liu, J., Wai, Y. C., Chen, Y., et al. (2006). Neuronal glutathione deficiency and age-dependent neurodegeneration in the EAAC1 deficient mouse. Nat. Neurosci. 9, 119-126. doi: 10.1038/nn1609

Arosio, P., Elia, L., and Poli, M. (2017). Ferritin, cellular iron storage and regulation. IUBMB Life 69, 414-422. doi: 10.1002/iub.1621

Asano, T., Komatsu, M., Yamaguchi-Iwai, Y., Ishikawa, F., Mizushima, N., and Iwai, K. (2011). Distinct mechanisms of ferritin delivery to lysosomes in irondepleted and iron-replete cells. Mol. Cell. Biol. 31, 2040-2052. doi: 10.1128/ MCB.01437-10

Ashraf, A., Clark, M., and So, P. W. (2018). The aging of iron man. Front. Aging Neurosci. 10:65. doi: 10.3389/fnagi.2018.00065

Bakhshayesh, B., Hosseininezhad, M., Saadat, S., Ansar, M., Ramezani, H., and Saadat, S. (2014). Iron overload is associated with perihematoma edema growth following intracerebral hemorrhage that may contribute to in-hospital mortality and long-term functional outcome. Curr. Neurovasc. Res. 11, 248-253. doi: 10.2174/15672026116661405301 24855 has been known for long, since blood spillover results in iron- $\mathrm{Hb}$ and iron-heme complexes at the extracellular milieu of brain parenchymal cells, thereby contributing to iron-induced lipid peroxidation and neuronal death. The review documents the beneficial effects of iron chelators such as DFO, physiological molecules with neuroprotective potential, and specific inhibitors of ferroptosis liproxstatin-1 or ferrostatin-1 in reducing neuron degeneration and improving neurologic deficits induced by ischemic and hemorrhagic stroke subtypes.

\section{AUTHOR CONTRIBUTIONS}

The three authors have contributed in a similar way to the writing of the article.

\section{FUNDING}

This study was supported by the following grants: Instituto de Salud Carlos III (ISCIII) INVICTUS PLUS RD16/0019/0020 that was susceptible to be co-financed by FEDER funds and Agència de Gestió d'Ajuts Universitaris i de Recerca 2017 SGR 1520. We acknowledge the funding received from "la Caixa" Foundation CI15-00009 and from the European Institute of Innovation and Technology (EIT) PoC-2016-SPAIN-04. EIT receives support from the European Union's Horizon 2020 research and innovation program.

Belaidi, A. A., Gunn, A. P., Wong, B. X., Ayton, S., Appukuttan, A. T., Roberts, B. R., et al. (2018). Marked age-related changes in brain iron homeostasis in amyloid protein precursor knockout mice. Neurotherapeutics 15, 1055-1062. doi: 10.1007/s13311-018-0656-x

Bickford, J. S., Ali, N. F., Nick, J. A., Al-Yahia, M., Beachy, D. E., Doré, S., et al. (2014). Endothelin-1-mediated vasoconstriction alters cerebral gene expression in iron homeostasis and eicosanoid metabolism. Brain Res. 1588, 25-36. doi: 10.1016/j.brainres.2014.09.022

Bradbury, M. W. (1997). Transport of iron in the blood-brain-cerebrospinal fluid system. J. Neurochem. 69, 443-454. doi: 10.1046/j.1471-4159.1997.69020443.x

Burdo, J. R., Menzies, S. L., Simpson, I. A., Garrick, L. M., Garrick, M. D., Dolan, K. G., et al. (2001). Distribution of divalent metal transporter 1 and metal transport protein 1 in the normal and Belgrade rat. J. Neurosci. Res. 66, 1198-1207. doi: 10.1002/jnr.1256

Carbonell, T., and Rama, M. (2007). Iron, oxidative stress and early neurological deterioration in ischemic stroke. Curr. Med. Chem. 14, 857-874. doi: 10.2174/ 092986707780363014

Carlson, G. C., Lin, R. E., Chen, Y., Brookshire, B. R., White, R. S., Lucki, I., et al. (2016). Dexras1 a unique ras-GTPase interacts with NMDA receptor activity and provides a novel dissociation between anxiety, working memory and sensory gating. Neuroscience 322, 408-415. doi: 10.1016/j.neuroscience. 2016.02.063

Castellanos, M., Puig, N., Carbonell, T., Castillo, J., Martinez, J. M., Rama, R., et al. (2002). Iron intake increases infarct volume after permanent middle cerebral artery occlusion in rats. Brain Res. 952, 1-6. doi: 10.1016/S0006-8993(02) 03179-7

Chamorro, Á, Dirnagl, U., Urra, X., and Planas, A. M. (2016). Neuroprotection in acute stroke: targeting excitotoxicity, oxidative and nitrosative stress, and inflammation. Lancet Neurol. 15, 869-881. doi: 10.1016/S1474-4422(16) 00114-9 
Cheah, J. H., Kim, S. F., Hester, L. D., Clancy, K. W., Patterson, S. E., Papadopoulos, V., et al. (2006). NMDA receptor-nitric oxide transmission mediates neuronal iron homeostasis via the GTPase Dexras1. Neuron 51, 431-440. doi: 10.1016/j.neuron.2006.07.011

Chen, G., Zhang, D., Fuchs, T. A., Manwani, D., Wagner, D. D., and Frenette, P. S. (2014). Heme-induced neutrophil extracellular traps contribute to the pathogenesis of sickle cell disease. Blood 123, 3818-3827. doi: 10.1182/blood2013-10-529982

Chen, H., Yoshioka, H., Kim, G. S., Jung, J. E., Okami, N., Sakata, H., et al. (2011). Oxidative stress in ischemic brain damage: mechanisms of cell death and potential molecular targets for neuroprotection. Antioxid. Redox Signal. 14, 1505-1517. doi: 10.1089/ars.2010.3576

Chen, L., Zhang, X., Chen-Roetling, J., and Regan, R. F. (2011). Increased striatal injury and behavioral deficits after intracerebral hemorrhage in hemopexin knockout mice. J. Neurosurg. 114, 1159-1167. doi: 10.3171/2010.10.JNS10861

Chen, L., Hambright, W. S., Na, R., and Ran, Q. (2015). Ablation of the ferroptosis inhibitor glutathione peroxidase 4 in neurons results in rapid motor neuron degeneration and paralysis. J. Biol. Chem. 290, 28097-28106. doi: 10.1074/jbc. M115.680090

Chen, Y., Khan, R. S., Cwanger, A., Song, Y., Steenstra, C., Bang, S., et al. (2013). Dexras1, a small GTPase, is required for glutamate-NMDA neurotoxicity. J. Neurosci. 33, 3582-3587. doi: 10.1523/JNEUROSCI.1497-12. 2013

Chen-Roetling, J., Cai, Y., Lu, X., and Regan, R. F. (2014). Hemin uptake and release by neurons and glia. Free Radic. Biol. Med. 48, 200-205. doi: 10.3109/10715762. 2013.859386

Chen-Roetling, J., Kamalapathy, P., Cao, Y., Song, W., Schipper, H. M., and Regan, R. F. (2017). Astrocyte heme oxygenase-1 reduces mortality and improves outcome after collagenase-induced intracerebral hemorrhage. Neurobiol. Dis. 102, 140-146. doi: 10.1016/j.nbd.2017.03.008

Chen-Roetling, J., Ma, S.-K., Cao, Y., Shah, A., and Regan, R. F. (2018). Hemopexin increases the neurotoxicity of hemoglobin when haptoglobin is absent. J. Neurochem. 145, 464-473. doi: 10.1111/jnc.14328

Chen-Roetling, J., and Regan, R. (2016). Haptoglobin increases the vulnerability of CD163-expressing neurons to hemoglobin. J. Neurochem. 139, 586-589. doi: $10.1111 /$ jnc. 13720

Chiou, B., Lucassen, E., Sather, M., Kallianpur, A., and Connor, J. (2018a). Semaphorin4A and H-ferritin utilize Tim-1 on human oligodendrocytes: a novel neuro-immune axis. Glia 66, 1317-1330. doi: 10.1002/glia.23313

Chiou, B., Neal, E. H., Bowman, A. B., Lippmann, E. S., Simpson, I. A., and Connor, J. R. (2018b). Endothelial cells are critical regulators of iron transport in a model of the human blood-brain barrier. J. Cereb. Blood Flow Metab. doi: 10.1177/0271678X18783372 [Epub ahead of print].

Cobley, J. N., Fiorello, M. L., and Bailey, D. M. (2018). 13 Reasons why the brain is susceptible to oxidative stress. Redox Biol. 15, 490-503. doi: 10.1016/j.redox. 2018.01.008

Conrad, M., and Sato, H. (2012). The oxidative stress-inducible cystine/glutamate antiporter, system Xc-: cystine supplier and beyond. Amino Acids 42, 231-246. doi: 10.1007/s00726-011-0867-5

Cui, H. J., He, H. Y., Yang, A. L., Zhou, H. J., Wang, C., Luo, J. K., et al. (2015). Efficacy of deferoxamine in animal models of intracerebral hemorrhage: a systematic review and stratified meta-analysis. PLoS One 10:e0127256. doi: 10.1371/journal.pone.0127256

Cui, L., Zhang, X., Yang, R., Liu, L., Wang, L., Li, M., et al. (2010). Baicalein is neuroprotective in rat MCAO model: role of 12/15-lipoxygenase, mitogenactivated protein kinase and cytosolic phospholipase A2. Pharmacol. Biochem. Behav. 96, 469-475. doi: 10.1016/j.pbb.2010.07.007

Das, A., Nag, S., Mason, A. B., and Barroso, M. M. (2016). Endosome-mitochondria interactions are modulated by iron release from transferrin. J. Cell Biol. 214, 831-845. doi: 10.1083/jcb.201 602069

Davalos, A., Fernandez-Real, J. M., Ricart, W., Soler, S., Molins, A., Planas, E., et al. (1994). Iron-related damage in acute ischemic stroke. Stroke 25, 1543-1546. doi: 10.1161/01.STR.25.8.1543

De Valk, B., Addicks, M. A., Gosriwatana, I., Lu, S., Hider, R. C., and Marx, J. J. M. (2000). Non-transferrin-bound iron is present in serum of hereditary haemochromatosis heterozygotes. Eur. J. Clin. Invest. 30, 248-251. doi: 10.1046/ j.1365-2362.2000.00628.x
Deane, R., Zheng, W., and Zlokovic, B. V. (2004). Brain capillary endothelium and choroid plexus epithelium regulate transport of transferrin-bound and free iron into the rat brain. J. Neurochem. 88, 813-820. doi: 10.1046/j.1471-4159.2003. 02221.x

DeGregorio-Rocasolano, N., Martí-Sistac, O., Ponce, J., Castelló-Ruiz, M., Millán, M., Guirao, V., et al. (2018). Iron-loaded transferrin (Tf) is detrimental whereas iron-free Tf confers protection against brain ischemia by modifying blood Tf saturation and subsequent neuronal damage. Redox Biol. 15, 143-158. doi: 10.1016/j.redox.2017.11.026

Demougeot, C., Van Hoecke, M., Bertrand, N., Prigent-Tessier, A., Mossiat, C., Beley, A., et al. (2004). Cytoprotective efficacy and mechanisms of the liposoluble iron chelator 2,2'-dipyridyl in the rat photothrombotic ischemic stroke model. J. Pharmacol. Exp. Ther. 311, 1080-1087. doi: 10.1124/jpet.104. 072744

Desestret, V., Brisset, J. C., Moucharrafie, S., Devillard, E., Nataf, S., Honnorat, J., et al. (2009). Early-stage investigations of ultrasmall superparamagnetic iron oxide-induced signal change after permanent middle cerebral artery occlusion in mice. Stroke 40, 1834-1841. doi: 10.1161/STROKEAHA.108.531269

Ding, H., Yan, C. Z., Shi, H., Zhao, Y. S., Chang, S. Y., Yu, P., et al. (2011). Hepcidin is involved in iron regulation in the ischemic brain. PLoS One 6:e25324. doi: 10.1371/journal.pone.0025324

Dixon, S. J., Lemberg, K. M., Lamprecht, M. R., Skouta, R., Zaitsev, E. M., Gleason, C. E., et al. (2012). Ferroptosis: an iron-dependent form of nonapoptotic cell death. Cell 149, 1060-1072. doi: 10.1016/j.cell.2012.03.042

Drecourt, A., Babdor, J., Dussiot, M., Petit, F., Goudin, N., Garfa-Traoré, M., et al. (2018). Impaired transferrin receptor palmitoylation and recycling in neurodegeneration with brain iron accumulation. Am. J. Hum. Genet. 102, 266-277. doi: 10.1016/j.ajhg.2018.01.003

Du, F., Qian, Z. M., Luo, Q., Yung, W. H., and Ke, Y. (2015). Hepcidin suppresses brain iron accumulation by downregulating iron transport proteins in ironoverloaded rats. Mol. Neurobiol. 52, 101-114. doi: 10.1007/s12035-014-8847-x

Duce, J. A., Tsatsanis, A., Cater, M. A., James, S. A., Robb, E., Wikhe, K., et al. (2010). An iron-export ferroxidase activity of APP is inhibited by zinc in Alzheimer's disease. Cell 142, 857-867. doi: 10.1016/j.cell.2010.08.014

Duck, K. A., Simpson, I. A., and Connor, J. R. (2017). Regulatory mechanisms for iron transport across the blood-brain barrier. Biochem. Biophys. Res. Commun. 494, 70-75. doi: 10.1016/j.bbrc.2017.10.083

Dutra, F. F., and Bozza, M. T. (2014). Heme on innate immunity and inflammation. Front. Pharmacol. 5:115. doi: 10.3389/fphar.2014.00115

Dziuba, N., and Lindahl, P. A. (2018). Low-molecular-mass iron in healthy blood plasma is not predominately ferric citrate. Metallomics 10, 802-817. doi: 10 . $1039 / \mathrm{c} 8 \mathrm{mt} 00055 \mathrm{~g}$

Feng, H., and Stockwell, B. R. (2018). Unsolved mysteries: how does lipid peroxidation cause ferroptosis? PLoS Biol. 16:e2006203. doi: 10.1371/journal. pbio. 2006203

Friedmann Angeli, J. P., Schneider, M., Proneth, B., Tyurina, Y. Y., Tyurin, V. A., Hammond, V. J., et al. (2014). Inactivation of the ferroptosis regulator Gpx4 triggers acute renal failure in mice. Nat. Cell Biol. 16, 1180-1191. doi: 10.1038/ ncb3064

Gaasch, J. A., Lockman, P. R., Geldenhuys, W. J., Allen, D. D., and Van Der Schyf, C. J. (2007). Brain iron toxicity: differential responses of astrocytes, neurons, and endothelial cells. Neurochem. Res. 32, 1196-1208. doi: 10.1007/s11064-0079290-4

Galea, J., Cruickshank, G., Teeling, J. L., Boche, D., Garland, P., Perry, V. H., et al. (2012). The intrathecal CD163-haptoglobin-hemoglobin scavenging system in subarachnoid hemorrhage. J. Neurochem. 121, 785-792. doi: 10.1111/j.14714159.2012.07716.x

Gamez, A., Carbonell, T., and Rama, R. (2003). Does nitric oxide contribute to iron-dependent brain injury after experimental cerebral ischaemia? J. Physiol. Biochem. 59, 249-254. doi: 10.1007/BF03179881

Gao, G., Zhang, N., Wang, Y., Wu, Q., Yu, P., Shi, Z., et al. (2017). Mitochondrial ferritin protects hydrogen peroxide-induced neuronal cell damage. Aging Dis. 8, 458-470. doi: 10.14336/AD.2016.1108

Gao, M., Monian, P., Quadri, N., Ramasamy, R., and Jiang, X. (2015). Glutaminolysis and transferrin regulate ferroptosis. Mol. Cell 59, 298-308. doi: 10.1016/j.molcel.2015.06.011

García-Yébenes, I., García-Culebras, A., Peña-Martínez, C., Fernández-López, D., Díaz-Guzmán, J., Negredo, P., et al. (2018). Iron overload exacerbates the risk 
of hemorrhagic transformation after tPA (tissue-type plasminogen activator) administration in thromboembolic stroke mice. Stroke 49, 2163-2172. doi: 10.1161/STROKEAHA.118.021540

García-Yébenes, I., Sobrado, M., Moraga, A., Zarruk, J. G., Romera, V. G., Pradillo, J. M., et al. (2012). Iron overload, measured as serum ferritin, increases brain damage induced by focal ischemia and early reperfusion. Neurochem. Int. 61, 1364-1369. doi: 10.1016/j.neuint.2012.09.014

Garton, A. L. A., Gupta, V. P., Christophe, B. R., and Connolly, E. S. (2017). Biomarkers of functional outcome in intracerebral hemorrhage: interplay between clinical metrics, CD163, and ferritin. J. Stroke Cerebrovasc. Dis. 26, 1712-1720. doi: 10.1016/j.jstrokecerebrovasdis.2017.03.035

Gazzina, S., Premi, E., Zanella, I., Biasiotto, G., Archetti, S., Cosseddu, M., et al. (2016). Iron in frontotemporal lobar degeneration: a new subcortical pathological pathway? Neurodegener. Dis. 16, 172-178. doi: 10.1159/000440843

Guan, H., Yang, H., Yang, M., Yanagisawa, D., Bellier, J. P., Mori, M., et al. (2017). Mitochondrial ferritin protects SH-SY5Y cells against $\mathrm{H} 2 \mathrm{O} 2$-induced oxidative stress and modulates $\alpha$-synuclein expression. Exp. Neurol. 291, 51-61. doi: 10.1016/j.expneurol.2017.02.001

Guirao, V., Martí-Sistac, O., DeGregorio-Rocasolano, N., Ponce, J., Dávalos, A., and Gasull, T. (2017). Specific rescue by ortho-hydroxy atorvastatin of cortical GABAergic neurons from previous oxygen/glucose deprivation: role of pCREB. J. Neurochem. 143, 359-374. doi: 10.1111/jnc.14210

Gutteridge, J. M., Richmond, R., and Halliwell, B. (1979). Inhibition of the iron-catalysed formation of hydroxyl radicals from superoxide and of lipid peroxidation by desferrioxamine. Biochem. J. 184, 469-472. doi: 10.1042/ bj1840469

Hadziahmetovic, M., Song, Y., Ponnuru, P., Iacovelli, J., Hunter, A., Haddad, N., et al. (2011). Age-dependent retinal iron accumulation and degeneration in hepcidin knockout mice. Investig. Ophthalmol. Vis. Sci. 52, 109-118. doi: 10. 1167/iovs.10-6113

Haeger, P., Alvarez, A., Leal, N., Adasme, T., Núñez, M. T., and Hidalgo, C. (2010). Increased hippocampal expression of the divalent metal transporter 1 (DMT1) mRNA variants $1 \mathrm{~B}$ and +IRE and DMT1 protein after NMDAreceptor stimulation or spatial memory training. Neurotox. Res. 17, 238-247. doi: 10.1007/s12640-009-9096-Z

Hambright, W. S., Fonseca, R. S., Chen, L., Na, R., and Ran, Q. (2017). Ablation of ferroptosis regulator glutathione peroxidase 4 in forebrain neurons promotes cognitive impairment and neurodegeneration. Redox Biol. 12, 8-17. doi: 10 . 1016/j.redox.2017.01.021

Hamdi, A., Roshan, T. M., Kahawita, T. M., Mason, A. B., Sheftel, A. D., and Ponka, P. (2016). Erythroid cell mitochondria receive endosomal iron by a "kiss-and-run" mechanism. Biochim. Biophys. Acta 1863, 2859-2867. doi: 10. 1016/j.bbamcr.2016.09.008

Han, J., Plummer, J., Liu, L., Byrd, A., Aschner, M., and Erikson, K. M. (2017). The impact of obesity on brain iron levels and $\alpha$-synuclein expression is regionally dependent. Nutr. Neurosci. doi: 10.1080/1028415X.2017.1387720 [Epub ahead of print].

Hanson, L. R., Roeytenberg, A., Martinez, P. M., Coppes, V. G., Sweet, D. C., Rao, R. J., et al. (2009). Intranasal deferoxamine provides increased brain exposure and significant protection in rat ischemic stroke. J. Pharmacol. Exp. Ther. 330, 679-686. doi: 10.1124/jpet.108.149807

Hatakeyama, T., Okauchi, M., Hua, Y., Keep, R. F., and Xi, G. (2013). Deferoxamine reduces neuronal death and hematoma lysis after intracerebral hemorrhage in aged rats. Transl. Stroke Res. 4, 546-553. doi: 10.1007/s12975-013-0270-5

He, Y., Karabiyikoglu, M., Hua, Y., Keep, R. F., and Xi, G. (2012). Ischemic preconditioning attenuates brain edema after experimental intracerebral hemorrhage. Transl. Stroke Res. 3, 180-187. doi: 10.1007/s12975-012-0171-z

Heidari, M., Johnstone, D. M., Bassett, B., Graham, R. M., Chua, A. C. G., House, M. J., et al. (2016). Brain iron accumulation affects myelin-related molecular systems implicated in a rare neurogenetic disease family with neuropsychiatric features. Mol. Psychiatry 21, 1599-1607. doi: 10.1038/mp.2015.192

Helal, G. K. (2008). Systemic administration of $\mathrm{Zn} 2+$ during the reperfusion phase of transient cerebral ischaemia protects rat hippocampus against iron-catalysed postischaemic injury. Clin. Exp. Pharmacol. Physiol. 35, 775-781. doi: 10.1111/ j.1440-1681.2007.04858.x

Hofmeijer, J., and Van Putten, M. J. (2012). Ischemic cerebral damage: an appraisal of synaptic failure. Stroke 43, 607-615. doi: 10.1161/STROKEAHA.111.632943
Huang, H., Chen, J., Lu, H., Zhou, M., Chai, Z., and Hu, Y. (2017). Iron-induced generation of mitochondrial ROS depends on AMPK activity. BioMetals 30, 623-628. doi: 10.1007/s10534-017-0023-0

Huang, S., Du, F., Li, L., Liu, Y., Liu, Y., Zhang, C., et al. (2014). Angiotensin II inhibits uptake of transferrin-bound iron but not nontransferrin-bound iron by cultured astrocytes. Neuropeptides 48, 161-166. doi: 10.1016/j.npep.2014.04.001

Hvidberg, V., Maniecki, M. B., Jacobsen, C., Højrup, P., Møller, H. J., and Moestrup, S. K. (2005). Identification of the receptor scavenging hemopexinheme complexes. Blood 106, 2572-2579. doi: 10.1182/blood-2005-03-1185

Jaffer, H., Adjei, I. M., and Labhasetwar, V. (2013). Optical imaging to map blood-brain barrier leakage. Sci. Rep. 3:3117. doi: 10.1038/srep03117

Jahanshad, N., Kohannim, O., Hibar, D. P., Stein, J. L., McMahon, K. L., de Zubicaray, G. I., et al. (2012). Brain structure in healthy adults is related to serum transferrin and the H63D polymorphism in the HFE gene. Proc. Natl. Acad. Sci. 109, E851-E859. doi: 10.1073/pnas.1105543109

Jeney, V., Eaton, J. W., Balla, G., and Balla, J. (2013). Natural history of the bruise: formation, elimination, and biological effects of oxidized hemoglobin. Oxid. Med. Cell. Longev. 2013:703571. doi: 10.1155/2013/703571

Ji, C., and Kosman, D. J. (2015). Molecular mechanisms of non-transferrinbound and transferring-bound iron uptake in primary hippocampal neurons. J. Neurochem. 133, 668-683. doi: 10.1111/jnc.13040

Karatas, H., Eun Jung, J., Lo, E. H., and van Leyen, K. (2018). Inhibiting 12/15lipoxygenase to treat acute stroke in permanent and tPA induced thrombolysis models. Brain Res. 1678, 123-128. doi: 10.1016/j.brainres.2017.10.024

Karuppagounder, S. S., Alin, L., Chen, Y., Brand, D., Bourassa, M. W., Dietrich, K., et al. (2018). $\mathrm{N}$-acetylcysteine targets 5 lipoxygenase-derived, toxic lipids and can synergize with PGE 2 to inhibit ferroptosis and improve outcomes following hemorrhagic stroke in mice. Ann. Neurol. 84, 854-872. doi: 10.1002/ana.25356

Kaur, C., and Ling, E. A. (1995). Transient expression of transferrin receptors and localisation of iron in amoeboid microglia in postnatal rats. J. Anat. 186, $165-173$.

Kawabata, H. (2018). Transferrin and transferrin receptors update. Free Radic. Biol. Med. doi: 10.1016/j.freeradbiomed.2018.06.037 [Epub ahead of print].

Kell, D. B. (2009). Iron behaving badly: inappropriate iron chelation as a major contributor to the aetiology of vascular and other progressive inflammatory and degenerative diseases. BMC Med. Genomics 2:2. doi: 10.1186/1755-8794-2-2

Khan, A. I., Liu, J., and Dutta, P. (2018). Iron transport kinetics through bloodbrain barrier endothelial cells. Biochim. Biophys. Acta Gen. Subj. 1862, $1168-$ 1179. doi: 10.1016/j.bbagen.2018.02.010

Khan, M., Sekhon, B., Jatana, M., Giri, S., Gilg, A. G., Sekhon, C., et al. (2004). Administration of N-Acetylcysteine after focal cerebral ischemia protects brain and reduces inflammation in a rat model of experimental stroke. J. Neurosci. Res. 76, 519-527. doi: 10.1002/jnr.20087

Klohs, J., Steinbrink, J., Bourayou, R., Mueller, S., Cordell, R., Licha, K., et al. (2009). Near-infrared fluorescence imaging with fluorescently labeled albumin: a novel method for non-invasive optical imaging of blood-brain barrier impairment after focal cerebral ischemia in mice. J. Neurosci. Methods 180, 126-132. doi: 10.1016/j.jneumeth.2009.03.002

Kumar, N., Rizek, P., Sadikovic, B., Adams, P. C., and Jog, M. (2016). Movement disorders associated with hemochromatosis. Can. J. Neurol. Sci. 43, 801-808. doi: $10.1017 /$ cjn. 2016.286

Kumar, S., Sheokand, N., Mhadeshwar, M. A., Raje, C. I., and Raje, M. (2012). Characterization of glyceraldehyde-3-phosphate dehydrogenase as a novel transferrin receptor. Int. J. Biochem. Cell Biol. 44, 189-199. doi: 10.1016/j.biocel. 2011.10.016

Latunde-Dada, G. O. (2017). Ferroptosis: role of lipid peroxidation, iron and ferritinophagy. Biochim. Biophys. Acta Gen. Subj. 1861, 1893-1900. doi: 10. 1016/j.bbagen.2017.05.019

LeBlanc, R. H., Chen, R., Selim, M. H., and Hanafy, K. A. (2016). Heme oxygenase-1-mediated neuroprotection in subarachnoid hemorrhage via intracerebroventricular deferoxamine. J. Neuroinflammation 13:244. doi: 10 . 1186/s12974-016-0709-1

Leclerc, J. L., Santiago-Moreno, J., Dang, A., Lampert, A. S., Cruz, P. E., Rosario, A. M., et al. (2018). Increased brain hemopexin levels improve outcomes after intracerebral hemorrhage. J. Cereb. Blood Flow Metab. 38, 1032-1046. doi: $10.1177 / 0271678 X 16679170$ 
Lee, F. H. F., Su, P., Xie, Y. F., Wang, K. E., Wan, Q., and Liu, F. (2016). Disrupting GluA2-GAPDH interaction affects axon and dendrite development. Sci. Rep. 6:30458. doi: 10.1038/srep30458

Lei, P., Ayton, S., Finkelstein, D. I., Spoerri, L., Ciccotosto, G. D., Wright, D. K., et al. (2012). Tau deficiency induces parkinsonism with dementia by impairing APP-mediated iron export. Nat. Med. 18, 291-295. doi: 10.1038/nm.2613

Leitner, D. F., and Connor, J. R. (2012). Functional roles of transferrin in the brain. Biochim. Biophys. Acta Gen. Subj. 1820, 393-402. doi: 10.1016/j.bbagen.2011. 10.016

Lewerenz, J., Ates, G., Methner, A., Conrad, M., and Maher, P. (2018). Oxytosis / ferroptosis - ( re- ) emerging roles for oxidative cell death in diseases of the central nervous system. Front. Neurosci. 12:214. doi: 10.3389/fnins.2018.00214

Li, J. Y., Paragas, N., Ned, R. M., Qiu, A., Viltard, M., Leete, T., et al. (2009). Scara5 Is a ferritin receptor mediating non-transferrin iron delivery. Dev. Cell 16, 35-46. doi: 10.1016/j.devcel.2008.12.002

Li, L., Fang, C. J., Ryan, J. C., Niemi, E. C., Lebron, J. A., Bjorkman, P. J., et al. (2010). Binding and uptake of $\mathrm{H}$-ferritin are mediated by human transferrin receptor-1. Proc. Natl. Acad. Sci. 107, 3505-3510. doi: 10.1073/pnas.0913 192107

Li, L., Hao, Y., Zhao, Y., Wang, H., Zhao, X., Jiang, Y., et al. (2018). Ferroptosis is associated with oxygen- glucose deprivation / reoxygenation- induced Sertoli cell death. Int. J. Mol. Med. 41, 3051-3062. doi: 10.3892/ijmm.2018. 3469

Li, Q., Han, X., Lan, X., Gao, Y., Wan, J., Durham, F., et al. (2017). Inhibition of neuronal ferroptosis protects hemorrhagic brain. JCI Insight 2:e90777. doi: 10.1172/jci.insight. 90777

Li, Y., Yang, H., Ni, W., and Gu, Y. (2017). Effects of deferoxamine on blood-brain barrier disruption after subarachnoid hemorrhage. PLoS One 12:e172784. doi: 10.1371/journal.pone.0172784

Linkermann, A., Skouta, R., Himmerkus, N., Mulay, S. R., Dewitz, C., De Zen, F., et al. (2014). Synchronized renal tubular cell death involves ferroptosis. Proc. Natl. Acad. Sci. 111, 16836-16841. doi: 10.1073/pnas.1415518111

Liu, R., Cao, S., Hua, Y., Keep, R. F., Huang, Y., and Xi, G. (2017). CD163 expression in neurons after experimental intracerebral hemorrhage. Stroke 48, 1369-1375. doi: 10.1161/STROKEAHA.117.016850

Lo, A. C. Y., Cheung, A. K. H., Hung, V. K. L., Yeung, C. M., He, Q. Y., Chiu, J. F., et al. (2007). Deletion of aldose reductase leads to protection against cerebral ischemic injury. J. Cereb. Blood Flow Metab. 27, 1496-1509. doi: 10.1038/sj. jcbfm.9600452

Luck, A. N., and Mason, A. B. (2012). Transferrin-mediated cellular iron delivery. Curr. Top. Membr. 69, 3-35. doi: 10.1016/B978-0-12-394390-3.00001-X

Ma, B., Day, J. P., Phillips, H., Slootsky, B., Tolosano, E., and Doré, S. (2016). Deletion of the hemopexin or heme oxygenase- 2 gene aggravates brain injury following stroma-free hemoglobin-induced intracerebral hemorrhage. J. Neuroinflammation 13, 1-12. doi: 10.1186/s12974-016-0490-1

Ma, J., Li, F., Gan, Z., Yu, Z., Bao, X., Shen, Y., et al. (2018). Different characteristics of hepcidin expression in IL- $6+/+$ and IL- $6-/$ - neurons and astrocytes treated with lipopolysaccharides. Neurochem. Res. 43, 1624-1630. doi: 10.1007/ s11064-018-2577-9

Mancias, J. D., Vaites, L. P., Nissim, S., Biancur, D. E., Kim, A. J., Wang, X., et al. (2015). Ferritinophagy via NCOA4 is required for erythropoiesis and is regulated by iron dependent HERC2-mediated proteolysis. eLife 4, 1-19. doi: 10.7554/eLife.10308

Man-man, X. U., Jun, W., and Jun-xia, X. I. E. (2017). Regulation of iron metabolism by hypoxia-inducible factors. Sheng Li Xue Bao 69, 598-610.

Marro, S., Chiabrando, D., Messana, E., Stolte, J., Turco, E., Tolosano, E., et al. (2010). Heme controls ferroportin 1 (FPN1) transcription involving Bach1, Nrf2 and a MARE/ARE sequence motif at position -7007 of the FPN1 promoter. Haematologica 95, 1261-1268. doi: 10.3324/haematol.2009.020123

Mayor, D., and Tymianski, M. (2018). Neurotransmitters in the mediation of cerebral ischemic injury. Neuropharmacology 134, 178-188. doi: 10.1016/j. neuropharm.2017.11.050

McCarthy, R. C., and Kosman, D. J. (2014). Glial cell ceruloplasmin and hepcidin differentially regulate iron efflux from brain microvascular endothelial cells. PLoS One 9:e89003. doi: 10.1371/journal.pone.0089003

McCarthy, R. C., Park, Y.-H., and Kosman, D. J. (2014). sAPP modulates iron efflux from brain microvascular endothelial cells by stabilizing the ferrous iron exporter ferroportin. EMBO Rep. 15, 809-815. doi: 10.15252/embr.201338064
McCarthy, R. C., Sosa, J. C., Gardeck, A. M., Baez, A. S., Lee, C.-H., and WesslingResnick, M. (2018). Inflammation-induced iron transport and metabolism by brain microglia. J. Biol. Chem. 293, 7853-7863. doi: 10.1074/jbc.RA118.001949

Mehdiratta, M., Kumar, S., Hackney, D., Schlaug, G., and Selim, M. (2008). Association between serum ferritin level and perihematoma edema volume in patients with spontaneous intracerebral hemorrhage. Stroke 39, 1165-1170. doi: 10.1161/STROKEAHA.107.501213

Mehta, S. H., Webb, R. C., Ergul, A., Tawfik, A., and Dorrance, A. M. (2004). Neuroprotection by tempol in a model of iron-induced oxidative stress in acute ischemic stroke. Am. J. Physiol. Regul. Integr. Comp. Physiol. 286, R283-R288. doi: 10.1152/ajpregu.00446.2002

Millan, M., Sobrino, T., Castellanos, M., Nombela, F., Arenillas, J. F., Riva, E., et al. (2007). Increased body iron stores are associated with poor outcome after thrombolytic treatment in acute stroke. Stroke 38, 90-95. doi: 10.1161/01.STR. 0000251798.25803.e0

Millerot, E., Prigent-Tessier, A. S., Bertrand, N. M., Faure, P. J. C., Mossiat, C. M., Giroud, M. E., et al. (2005). Serum ferritin in stroke: a marker of increased body iron stores or stroke severity? J. Cereb. Blood Flow Metab. 25, 1386-1393. doi: $10.1038 /$ sj.jcbfm.9600140

Millerot-Serrurot, E., Bertrand, N., Mossiat, C., Faure, P., Prigent-Tessier, A., Garnier, P., et al. (2008). Temporal changes in free iron levels after brain ischemia. Relevance to the timing of iron chelation therapy in stroke. Neurochem. Int. 52, 1442-1448. doi: 10.1016/j.neuint.2008. 04.002

Morris, G., Berk, M., Carvalho, A. F., Maes, M., Walker, A. J., and Puri, B. K. (2018). Why should neuroscientists worry about iron? The emerging role of ferroptosis in the pathophysiology of neuroprogressive diseases. Behav. Brain Res. 341, 154-175. doi: 10.1016/j.bbr.2017.12.036

Muñoz, P., Humeres, A., Elgueta, C., Kirkwood, A., Hidalgo, C., and Núñez, M. T. (2011). Iron mediates N-Methyl-D-aspartate receptor-dependent stimulation of calcium-induced pathways and hippocampal synaptic plasticity. J. Biol. Chem. 286, 13382-13392. doi: 10.1074/jbc.M110.213785

Nagy, Z., and Nardai, S. (2017). Cerebral ischemia/repefusion injury: from bench space to bedside. Brain Res. Bull. 134, 30-37. doi: 10.1016/j.brainresbull.2017. 06.011

Nakamura, T., Keep, R. F., Hua, Y., Schallert, T., Hoff, J. T., and Xi, G. (2004). Deferoxamine-induced attenuation of brain edema and neurological deficits in a rat model of intracerebral hemorrhage. J. Neurosurg. 100, 672-678. doi: 10.3171/jns.2004.100.4.0672

Nandar, W., and Connor, J. R. (2011). HFE gene variants affect iron in the brain. J. Nutr. 141, 729S-739S. doi: 10.3945/jn.110.130351

Nicolas, G., Bennoun, M., Devaux, I., Beaumont, C., Grandchamp, B., Kahn, A., et al. (2001). Lack of hepcidin gene expression and severe tissue iron overload in upstream stimulatory factor 2 (USF2) knockout mice. Proc. Natl. Acad. Sci. 98, 8780-8785. doi: 10.1073/pnas.151179498

Nicolas, G., Bennoun, M., Porteu, A., Mativet, S., Beaumont, C., Grandchamp, B., et al. (2002a). Severe iron deficiency anemia in transgenic mice expressing liver hepcidin. Proc. Natl. Acad. Sci. 99, 4596-4601.

Nicolas, G., Chauvet, C., Viatte, L., Danan, J. L., Bigard, X., Devaux, I., et al. (2002b). The gene encoding the iron regulatory peptide hepcidin is regulated by anemia, hypoxia, and inflammation. J. Clin. Invest. 110, 1037-1044.

Ottestad-Hansen, S., Hu, Q. X., Follin-Arbelet, V. V., Bentea, E., Sato, H., Massie, A., et al. (2018). The cystine-glutamate exchanger (xCT, Slc7a11) is expressed in significant concentrations in a subpopulation of astrocytes in the mouse brain. Glia 66, 951-970. doi: 10.1002/glia.23294

Park, U. J., Lee, Y. A., Won, S. M., Lee, J. H., Kang, S. H., Springer, J. E., et al. (2011). Blood-derived iron mediates free radical production and neuronal death in the hippocampal CA1 area following transient forebrain ischemia in rat. Acta Neuropathol. 121, 459-473. doi: 10.1007/s00401-0100785-8

Pelizzoni, I., Macco, R., Morini, M. F., Zacchetti, D., Grohovaz, F., and Codazzi, F. (2011). Iron handling in hippocampal neurons: activity-dependent iron entry and mitochondria-mediated neurotoxicity. Aging Cell 10, 172-183. doi: 10. 1111/j.1474-9726.2010.00652.x

Pelizzoni, I., Zacchetti, D., Smith, C. P., Grohovaz, F., and Codazzi, F. (2012). Expression of divalent metal transporter 1 in primary hippocampal neurons: reconsidering its role in non-transferrin-bound iron influx. J. Neurochem. 120, 269-278. doi: 10.1111/j.1471-4159.2011.07578.x 
Pellegrino, R. M., Boda, E., Montarolo, F., Boero, M., Mezzanotte, M., Saglio, G., et al. (2016). Transferrin receptor 2 dependent alterations of brain iron metabolism affect anxiety circuits in the mouse. Sci. Rep. 6:30725. doi: 10.1038/ srep30725

Perez de la Ossa, N., Sobrino, T., Silva, Y., Blanco, M., Millan, M., Gomis, M., et al. (2010). Iron-related brain damage in patients with intracerebral hemorrhage. Stroke 41, 810-813. doi: 10.1161/STROKEAHA.109.570168

Peters, D. G., Purnell, C. J., Haaf, M. P., Yang, Q. X., Connor, J. R., and Meadowcroft, M. D. (2018). Dietary lipophilic iron accelerates regional brain iron-load in C57BL6 mice. Brain Struct. Funct. 223, 1519-1536. doi: 10.1007/ s00429-017-1565-1

Petrova, J., Manolov, V., Hadjidekova, S., Hadjiev, E., Bogov, B., Marinov, B., et al. (2015). Is there a link between changes in levels of hepcidin and stroke? Clin. Lab. 61, 1935-1939.

Philpott, C. C., and Ryu, M. S. (2014). Special delivery: distributing iron in the cytosol of mammalian cells. Front. Pharmacol. 5:173. doi: 10.3389/fphar.2014. 00173

Philpott, C. C., Ryu, M. S., Frey, A., and Patel, S. (2017). Cytosolic iron chaperones: proteins delivering iron cofactors in the cytosol of mammalian cells. J. Biol. Chem. 292, 12764-12771. doi: 10.1074/jbc.R117.791962

Piloni, N. E., Caro, A. A., and Puntarulo, S. (2018). Iron overload prevents oxidative damage to rat brain after chlorpromazine administration. BioMetals doi: 10 . 1007/s10534-018-0104-8 [Epub ahead of print].

Raje, C. I., Kumar, S., Harle, A., Nanda, J. S., and Raje, M. (2007). The macrophage cell surface glyceraldehyde-3-phosphate dehydrogenase is a novel transferrin receptor. J. Biol. Chem. 282, 3252-3261. doi: 10.1074/jbc.M608328200

Ramos, P., Santos, A., Pinto, N. R., Mendes, R., Magalhães, T., and Almeida, A. (2014). Iron levels in the human brain: a post-mortem study of anatomical region differences and age-related changes. J. Trace Elem. Med. Biol. 28, 13-17. doi: 10.1016/j.jtemb.2013.08.001

Rathnasamy, G., Murugan, M., Ling, E. A., and Kaur, C. (2016). Hypoxiainduced iron accumulation in oligodendrocytes mediates apoptosis by eliciting endoplasmic reticulum stress. Mol. Neurobiol. 53, 4713-4727. doi: 10.1007/ s12035-015-9389-6

Ravasi, G., Pelucchi, S., Buoli Comani, G., Greni, F., Mariani, R., Pelloni, I., et al. (2018). Hepcidin regulation in a mouse model of acute hypoxia. Eur. J. Haematol. 100, 636-643. doi: 10.1111/ejh.13062

Recalcati, S., Gammella, E., Buratti, P., and Cairo, G. (2017). Molecular regulation of cellular iron balance. IUBMB Life 69, 389-398. doi: 10.1002/iub.1628

Righy, C., Bozza, M. T., Oliveira, M. F., and Bozza, F. A. (2016). Molecular, cellular and clinical aspects of intracerebral hemorrhage: are the enemies within? Curr. Neuropharmacol. 14, 392-402. doi: 10.2174/1570159X14666151230110058

Righy, C., Turon, R., de Freitas, G., Japiassu, A. M., Faria Neto, H. C. C., Bozza, M., et al. (2018). Hemoglobin metabolism by-products are associated with an inflammatory response in patients with hemorrhagic stroke. Rev. Bras. Ter. Intens. 30, 21-27. doi: 10.5935/0103-507x.20180003

Sakamoto, K., Suzuki, T., Takahashi, K., Koguchi, T., Hirayama, T., Mori, A., et al. (2018). Iron-chelating agents attenuate NMDA-Induced neuronal injury via reduction of oxidative stress in the rat retina. Exp. Eye Res. 171, 30-36. doi: 10.1016/j.exer.2018.03.008

Sangkhae, V., and Nemeth, E. (2017). Regulation of the iron homeostatic hormone hepcidin. Adv. Nutr. Int. Rev. J. 8, 126-136. doi: 10.3945/an.116.013961

Sankar, S. B., Donegan, R. K., Shah, K. J., Reddi, A. R., and Wood, L. B. (2018). Heme and hemoglobin suppress amyloid $\beta$-mediated inflammatory activation of mouse astrocytes. J. Biol. Chem. 293, 11358-11373. doi: 10.1074/jbc.RA117. 001050

Seiler, A., Schneider, M., Förster, H., Roth, S., Wirth, E. K., Culmsee, C., et al. (2008). Glutathione peroxidase 4 senses and translates oxidative stress into 12/15-lipoxygenase dependent- and AIF-mediated cell death. Cell Metab. 8, 237-248. doi: 10.1016/j.cmet.2008.07.005

Sheokand, N., Malhotra, H., Chauhan, A. S., Kumar, M., Chaudhary, S., Patidar, A., et al. (2016). Reverse overshot water-wheel retroendocytosis of apotransferrin extrudes cellular iron. J. Cell Sci. 129, 843-853. doi: 10.1242/jcs. 180356

Shin, J. A., Kim, Y. A., Kim, H. W., Kim, H. S., Lee, K. E., Kang, J. L., et al. (2018). Iron released from reactive microglia by noggin improves myelin repair in the ischemic brain. Neuropharmacology 133, 202-215. doi: 10.1016/j.neuropharm. 2018.01.038
Sillerova, T., Zivny, J., Vyoral, D., and Petrak, J. (2012). Nutritional hepatic iron overload is not prevented by parenteral hepcidin substitution therapy in mice. Br. J. Nutr. 108, 1723-1725. doi: 10.1017/S0007114512000116

Simpson, I. A., Ponnuru, P., Klinger, M. E., Myers, R. L., Devraj, K., Coe, C. L., et al. (2015). A novel model for brain iron uptake: introducing the concept of regulation. J. Cereb. Blood Flow Metab. 35, 48-57. doi: 10.1038/jcbfm.2014.168

Skjorringe, T., Burkhart, A., Johnsen, K. B., and Moos, T. (2015). Divalent metal transporter 1 (DMT1) in the brain: implications for a role in iron transport at the blood-brain barrier, and neuronal and glial pathology. Front. Mol. Neurosci. 8:19. doi: 10.3389/fnmol.2015.00019

Slomka, A., Switoñska, M., and Zekanowska, E. (2015). Hepcidin levels are increased in patients with acute ischemic stroke: preliminary report. J. Stroke Cerebrovasc. Dis. 24, 1570-1576. doi: 10.1016/j.jstrokecerebrovasdis.2015.03.031

Sonnweber, T., Nachbaur, D., and Schroll, A. (2014). Hypoxia induced downregulation of hepcidin is mediated by platelet derived growth factor BB. Gut 63, 1951-1959. doi: 10.1136/gutjnl-2013-305317

Soria, F. N., Pérez-samartín, A., Martin, A., Gona, K. B., Llop, J., Szczupak, B., et al. (2014). Extrasynaptic glutamate release through cystine / glutamate antiporter contributes to ischemic damage. J. Clin. Inverstig. 124, 3645-3655. doi: 10.1172/ JCI71886

Soria, F. N., Zabala, A., Pampliega, O., Palomino, A., Miguelez, C., Ugedo, L., et al. (2016). Cystine/glutamate antiporter blockage induces myelin degeneration. Glia 64, 1381-1395. doi: 10.1002/glia.23011

Sterling, J., Gutthaa, S., Song, Y., Song, D., Hadziahmetovic, M., and Dunaief, J. L. (2017). Iron importers Zip8 and Zip14 are expressed in retina and regulated by retinal iron levels JacobHHS public access. Exp. Eye Res. 155, 15-23. doi: 10.1016/j.exer.2016.12.008

Strazielle, N., and Ghersi-Egea, J.-F. (2016). Potential pathways for CNS drug delivery across the blood-cerebrospinal fluid barrier. Curr. Pharm. Des. 22, 4942-4958. doi: 10.2174/1381612822666160726112115

Sweeny, E. A., Singh, A. B., Chakravarti, R., Martinez-Guzman, O., Saini, A., Haque, M. M., et al. (2018). Glyceraldehyde 3-phosphate dehydrogenase is a chaperone that allocates labile heme in cells. J. Biol. Chem. 293, 14557-14568. doi: 10.1074/jbc.RA118.004169

Tan, G., Liu, L., He, Z., Sun, J., Xing, W., and Sun, X. (2016). Role of hepcidin and its downstream proteins in early brain injury after experimental subarachnoid hemorrhage in rats. Mol. Cell. Biochem. 418, 31-38. doi: 10.1007/s11010-0162730-1

Tauchenová, L., Køížová, B., Kubánek, M., Fraòková, S., Melenovsk $\iota$, V., Tintìra, J., et al. (2016). Successful treatment of iron-overload cardiomyopathy in hereditary hemochromatosis with deferoxamine and deferiprone. Can. J. Cardiol. 32, 1574.e1-1574.e3. doi: 10.1016/j.cjca.2016.07.589

Tian, Y., He, Y., Song, W., Zhang, E., and Xia, X. (2017). Neuroprotective effect of deferoxamine on N-methyl-d-aspartate-induced excitotoxicity in RGC-5 cells. Acta Biochim. Biophys. Sin. 49, 827-834. doi: 10.1093/abbs/gmx082

Todorich, B., Zhang, X., and Connor, J. R. (2011). H-ferritin is the major source of iron for oligodendrocytes. Glia 59, 927-935. doi: 10.1002/glia.21164

Todorich, B., Zhang, X., Slagle-Webb, B., Seaman, W. E., and Connor, J. R. (2008). Tim-2 is the receptor for H-ferritin on oligodendrocytes. J. Neurochem. 107, 1495-1505. doi: 10.1111/j.1471-4159.2008.05678.x

Tripathi, A. K., Karmakar, S., Asthana, A., Ashok, A., Desai, V., Baksi, S., et al. (2017). Transport of non-transferrin bound iron to the brain: implications for Alzheimer's disease. J. Alzheimer's Dis. 58, 1109-1119. doi: 10.3233/JAD-170097

Truman-Rosentsvit, M., Berenbaum, D., Spektor, L., Cohen, L. A., BelizowskyMoshe, S., Lifshitz, L., et al. (2018). Ferritin is secreted via 2 distinct nonclassical vesicular pathways. Blood 131, 342-352. doi: 10.1182/blood-2017-02-768580

Tuo, Q., Lei, P., Jackman, K. A., Li, X., Xiong, H., Li, X., et al. (2017). Tau-mediated iron export prevents ferroptotic damage after ischemic stroke. Mol. Psychiatry 22, 1520-1530. doi: 10.1038/mp.2017.171

Turkmen, S., Gonenc, O. C., Karaca, Y., Mentese, A., Demir, S., Beyhun, E., et al. (2016). The effect of ethyl pyruvate and $\mathrm{N}$-acetylcysteine on ischemiareperfusion injury in an experimental model of ischemic stroke. Am. J. Emerg. Med. 34, 1804-1807. doi: 10.1016/j.ajem.2016.06.003

Uranga, R. M., and Salvador, G. A. (2018). Unraveling the burden of iron in neurodegeneration: intersections with amyloid beta peptide pathology. Oxid. Med. Cell. Longev. 2018:2850341. doi: 10.1155/2018/2850341 
Van Dijk, B. A. C., Laarakkers, C. M. M., Klaver, S. M., Jacobs, E. M. G., Van Tits, L. J. H., Janssen, M. C. H., et al. (2008). Serum hepcidin levels are innately low in HFE-related haemochromatosis but differ between C282Y-homozygotes with elevated and normal ferritin levels. Br. J. Haematol. 142, 979-985. doi: 10.1111/j.1365-2141.2008.07273.x

Van Hoecke, M., Prigent-Tessier, A., Bertrand, N., Prevotat, L., Marie, C., and Beley, A. (2005). Apoptotic cell death progression after photothrombotic focal cerebral ischaemia: effects of the lipophilic iron chelator 2,2'-dipyridyl. Eur. J. Neurosci. 22, 1045-1056. doi: 10.1111/j.1460-9568.2005.04297.x

Vela, D. (2018). Hepcidin, an emerging and important player in brain iron homeostasis. J. Transl. Med. 16:25. doi: 10.1186/s12967-018-1399-5

Wan, L., Nie, G., Zhang, J., and Zhao, B. (2012). Overexpression of human wildtype amyloid- $\beta$ protein precursor decreases the iron content and increases the oxidative stress of neuroblastoma SH-SY5Y cells. J. Alzheimer's Dis. 30, 523-530. doi: 10.3233/JAD-2012-111169

Wang, J., and Doré, S. (2007). Inflammation after intracerebral hemorrhage. J. Cereb. Blood Flow Metab. 27, 894-908. doi: 10.1038/sj.jcbfm.9600403

Ward, R. J., Zucca, F. A., Duyn, J. H., Crichton, R., and Zecca, L. (2014). The role of iron in brain ageing and neurodegenerative disorders. Lancet Neurol. 13, 1045-1060. doi: 10.1016/S1474-4422(14)70117-6

Watts, S. D., Torres-Salazar, D., Divito, C. B., and Amara, S. G. (2014). Cysteine transport through excitatory amino acid transporter 3 (EAAT3). PLoS One 9:e109245. doi: 10.1371/journal.pone.0109245

West, A. P., Bennett, M. J., Sellers, V. M., Andrews, N. C., Enns, C. A., and Bjorkman, P. J. (2000). Comparison of the interactions of transferrin receptor and transferrin receptor 2 with transferrin and the hereditary hemochromatosis protein HFE. J. Biol. Chem. 275, 38135-38138. doi: 10.1074/jbc.C000664200

White, R. S., Bhattacharya, A. K., Chen, Y., Byrd, M., McMullen, M. F., Siegel, S. J., et al. (2016). Lysosomal iron modulates NMDA receptor-mediated excitation via small GTPase, Dexras1. Mol. Brain 9:38. doi: 10.1186/s13041-016-0220-8

Worthen, C. A., and Enns, C. A. (2014). The role of hepatic transferrin receptor 2 in the regulation of iron homeostasis in the body. Front. Pharmacol. 5:34. doi: 10.3389/fphar.2014.00034

Wu, C., Zhao, W., Yu, J., Li, S., Lin, L., and Chen, X. (2018). Induction of ferroptosis and mitochondrial dysfunction by oxidative stress in PC12 cells. Sci. Rep. 8:574. doi: 10.1038/s41598-017-18935-1

Wu, J., Hua, Y., Keep, R. F., Nakamura, T., Hoff, J. T., and Xi, G. (2003). Iron and iron-handling proteins in the brain after intracerebral hemorrhage. Stroke 34, 2964-2969. doi: 10.1161/01.STR.0000103140.52838.45

Xing, Y., Hua, Y., Keep, R. F., and Xi, G. (2009). Effects of deferoxamine on brain injury after transient focal cerebral ischemia in rats with hyperglycemia. Brain Res. 1291, 113-121. doi: 10.1016/j.brainres.2009.07.032

Xiong, X. Y., Chen, J., Zhu, W. Y., Zhao, T., Zhong, Q., Zhou, K., et al. (2015). Serum hepcidin concentrations correlate with serum iron level and outcome in patients with intracerebral hemorrhage. Neurol. Sci. 36, 1843-1849. doi: 10.1007/s10072-015-2266-2

Xiong, X. Y., Liu, L., Wang, F. X., Yang, Y. R., Hao, J. W., Wang, P. F., et al. (2016). Toll-like receptor 4/MyD88-mediated signaling of hepcidin expression causing brain iron accumulation, oxidative injury, and cognitive impairment after intracerebral hemorrhage. Circulation 134, 1025-1038. doi: 10.1161/ CIRCULATIONAHA.116.021881

Yang, G., Hu, R., Zhang, C., Qian, C., and Luo, Q. (2016). A combination of serum iron, ferritin and transferrin predicts outcome in patients with intracerebral hemorrhage. Sci. Rep. 6:21970. doi: 10.1038/srep21970
Yang, L., Fan, M., Du, F., Gong, Q., Bi, Z. G., Zhu, Z. J., et al. (2012). Hypoxic preconditioning increases iron transport rate in astrocytes. Biochim. Biophys. Acta Mol. Basis Dis. 1822, 500-508. doi: 10.1016/j.bbadis.2011. 12.004

Yang, Y., Dong, B., Lu, J., Wang, G., and Yu, Y. (2018). Hemopexin reduces bloodbrain barrier injury and protects synaptic plasticity in cerebral ischemic rats by promoting EPCs through the HO-1 pathway. Brain Res. 1699, 177-185. doi: 10.1016/j.brainres.2018.08.008

You, L. H., Li, Z., Duan, X. L., Zhao, B. L., Chang, Y. Z., and Shi, Z. H. (2016). Mitochondrial ferritin suppresses MPTP-induced cell damage by regulating iron metabolism and attenuating oxidative stress. Brain Res. 1642, 33-42. doi: 10.1016/j.brainres.2016.03.023

Yu, J., Guo, Y., Sun, M., Li, B., Zhang, Y., and Li, C. (2009). Iron is a potential key mediator of glutamate excitotoxicity in spinal cord motor neurons. Brain Res. 1257, 102-107. doi: 10.1016/j.brainres.2008. 12.030

Zeng, L., Tan, L., Li, H., Zhang, Q., Li, Y., and Guo, J. (2018). Deferoxamine therapy for intracerebral hemorrhage: a systematic review. PLoS One 13:e0193615. doi: 10.1371/journal.pone.0193615

Zhang, H., Park, J. H., Maharjan, S., Park, J. A., Choi, K. S., Park, H., et al. (2017). Sac-1004, a vascular leakage blocker, reduces cerebral ischemia-reperfusion injury by suppressing blood-brain barrier disruption and inflammation. J. Neuroinflammation 14:122. doi: 10.1186/s12974-017-0897-3

Zhang, Z., Wu, Y., Yuan, S., Zhang, P., Zhang, J., Li, H., et al. (2018). Glutathione peroxidase 4 participates in secondary brain injury through mediating ferroptosis in a rat model of intracerebral hemorrhage. Brain Res. 1701, 112-125. doi: 10.1016/j.brainres.2018.09.012

Zhao, J., Xiang, X., Zhang, H., Jiang, D., Liang, Y., Qing, W., et al. (2018). CHOP induces apoptosis by affecting brain iron metabolism in rats with subarachnoid hemorrhage. Exp. Neurol. 302, 22-33. doi: 10.1016/j.expneurol.2017. 12.015

Zhao, X., Song, S., Sun, G., Zhang, J., Strong, R., Zhang, L., et al. (2011). Cytoprotective role of haptoglobin in brain after experimental intracerebral hemorrhage. Acta Neurochir. Suppl. 111, 107-112. doi: 10.1007/978-3-70910693-8_17

Zhou, Y. F., Zhang, C., Yang, G., Qian, Z. M., Zhang, M. W., Ma, J., et al. (2017). Hepcidin protects neuron from hemin-mediated injury by reducing iron. Front. Physiol. 8:332. doi: 10.3389/fphys.2017.00332

Zille, M., Karuppagounder, S. S., Chen, Y., Gough, P. J., Bertin, J., Finger, J., et al. (2017). Neuronal death after hemorrhagic stroke in vitro and in vivo shares features of ferroptosis and necroptosis. Stroke 48, 1033-1043. doi: 10.1161/ STROKEAHA.116.015609

Conflict of Interest Statement: The authors declare that the research was conducted in the absence of any commercial or financial relationships that could be construed as a potential conflict of interest.

Copyright (c) 2019 DeGregorio-Rocasolano, Marti-Sistac and Gasull. This is an openaccess article distributed under the terms of the Creative Commons Attribution License (CC BY). The use, distribution or reproduction in other forums is permitted, provided the original author(s) and the copyright owner(s) are credited and that the original publication in this journal is cited, in accordance with accepted academic practice. No use, distribution or reproduction is permitted which does not comply with these terms. 